\title{
Numerical Analysis of Mixed Convective Heat Transfer from a Square Cylinder Utilizing Nanofluids with Multi-Phase Modelling Approach
}

\author{
Rajendra S. Rajpoot ${ }^{1}$, Shanmugam. Dhinakaran ${ }^{1}$ (D) and Md. Mahbub Alam ${ }^{2, *(D)}$ \\ 1 The Centre for Fluid Dynamics, Department of Mechanical Engineering, Indian Institute of \\ Technology Indore, Simrol, Indore 453552, India; phd1401203006@iiti.ac.in (R.S.R.); sdhina@iiti.ac.in (S.D.) \\ 2 Institute for Turbulence Control, Harbin Institute of Technology, Shenzhen 518055, China \\ * Correspondence: alamm28@yahoo.com or alam@hit.edu.cn
}

Citation: Rajpoot, R.S.;

Dhinakaran, S.; Alam, M.M.

Numerical Analysis of Mixed

Convective Heat Transfer from a Square Cylinder Utilizing Nanofluids with Multi-Phase Modelling

Approach. Energies 2021, 14, 5485.

https://doi.org/10.3390/en14175485

Academic Editor: Gabriela Huminic

Received: 19 July 2021

Accepted: 21 August 2021

Published: 2 September 2021

Publisher's Note: MDPI stays neutral with regard to jurisdictional claims in published maps and institutional affiliations.

Copyright: (c) 2021 by the authors. Licensee MDPI, Basel, Switzerland. This article is an open access article distributed under the terms and conditions of the Creative Commons Attribution (CC BY) license (https:/ / creativecommons.org/licenses/by/ $4.0 /)$.
Abstract: The present study deals with the numerical simulation of mixed convective heat transfer from an unconfined heated square cylinder using nanofluids $\left(\mathrm{Al}_{2} \mathrm{O}_{3}\right.$-water) for Reynolds number (Re) 10-150, Richardson number (Ri) 0-1, and nanoparticles volume fractions ( $\varphi$ ) 0-5\%. Two-phase modelling approach (i.e., Eulerian-mixture model) is adopted to analyze the flow and heat transfer characteristics of nanofluids. A square cylinder with a constant temperature higher than that of the ambient is exposed to a uniform flow. The governing equations are discretized and solved by using a finite volume method employing the SIMPLE algorithm for pressure-velocity coupling. The thermo-physical properties of nanofluids are calculated from the theoretical models using a singlephase approach. The flow and heat transfer characteristics of nanofluids are studied for considered parameters and compared with those of the base fluid. The temperature field and flow structure around the square cylinder are visualized and compared for single and multi-phase approaches. The thermal performance under thermal buoyancy conditions for both steady and unsteady flow regimes is presented. Minor variations in flow and thermal characteristics are observed between the two approaches for the range of nanoparticle volume fractions considered. Variation in $\varphi$ affects $C_{D}$ when Reynolds number is varied from 10 to 50. Beyond Reynolds number 50, no significant change in $C_{D}$ is observed with change in $\varphi$. The local and mean Nusselt numbers increase with Reynolds number, Richardson number, and nanoparticle volume fraction. For instance, the mean Nusselt number of nanofluids at $R e=100, \varphi=5 \%$, and $R i=1$ is approximately $12.4 \%$ higher than that of the base fluid. Overall, the thermal enhancement ratio increases with $\varphi$ and decreases with $R e$ regardless of $R i$ variation.

Keywords: nanofluids; mixed convection; mixture model; heated square cylinder; bluff body

\section{Introduction}

Nanofluids are the engineered colloidal suspension of nanosized particles (10-100 nm) in a base fluid [1]. They have greater thermal conductivity compared to their base fluids and are considered smart fluids because the heat transfer rates can be controlled to some extent by varying nanoparticle concentration in the base fluid [2]. Nanofluids find applications in nuclear reactors [3], electronic cooling [4], heat exchanger [5], heating buildings in cold regions [6], drying of various materials [7], and automotive applications [8,9]. Numerous experimental and numerical studies have proved that heat transfer rates augment with an increase in nanoparticle volume fractions in base fluid [10-13]. As nanofluids enhance the heat transfer rates when they flow over the surface of a hot body, it would be interesting to investigate the flow and heat transfer from a hot square cylinder placed in a uniform stream of nanofluid. 


\section{Review of Previous Work}

The complexity involved in flow over a heated square cylinder is that it provides generous flow and heat transfer physics, namely recirculation, vortex shedding, wake region, and shear layer interaction $[14,15]$. Over the past few decades, a considerable amount of studies dealing with the single-phase modelling approach have been published [16]. Etminan-Farooji et al. [17] investigated numerically the effects of using nanofluids in unconfined flow past a hot square cylinder. The heat transfer characteristics of $\mathrm{Al}_{2} \mathrm{O}_{3}$ and $\mathrm{CuO}$ nanofluids are studied by varying effective parameters such as particle volume concentrations, nanoparticle diameters $\left(d_{n p}\right)$, and base fluid. They found that heat transfer increases with a rise in nanoparticle volume fraction $(\varphi)$ but falls with nanoparticle diameter $\left(d_{n p}\right)$. The effect of $\varphi$ on the heat transfer is more significant than that of $d_{n p}$. They also revealed $\varphi$ has more effect on the heat transfer than the particle diameter $\left(d_{n p}\right)$. For the same governing parameters, $\mathrm{CuO}$ nanofluid $\left(\varphi=4 \% \& d_{n p}=30\right)$ and $\mathrm{Al}_{2} \mathrm{O}_{3}$ nanofluid ( $\varphi=4 \% \& d_{n p}=30$ ) augmented heat transfer by $25.1 \%$ and $23.6 \%$ relative to the base fluid, respectively. Valipour et al. [18] who worked on the same geometry and flow configuration found that the Nusselt number $(\mathrm{Nu})$ increases with nanoparticle volume fraction $(\varphi)$. The effect of nanoparticles volume fraction on the drag coefficient $\left(C_{D}\right)$ is significant at low $R e$, and increasing $\varphi$ augments the drag coefficient.

Some researchers attempted to use multi-phase modelling approaches to predict the behaviour of nanofluids. Although suspension of a nanofluid is inherently a twophase fluid, the two-phase modelling approaches may offer realistic results compared to single-phase approaches. Multi-phase modelling methods can be categorized into Eulerian-Eulerian and Eulerian-Lagrangian [19]. The Eulerian-Eulerian methods are further divided into Mixture, Eulerian, and Volume of fluids (VOF) models. Overall mixture model is recommended while comparing single-phase, VOF, and Eulerian models because it takes less run time and CPU usage to model flow and heat transfer behaviours. Still, the difference between the model results is marginal [20,21]. Bizhaem and Abbassi [22] conducted numerical simulations of nanofluid flow in a helical tube maintained at a constant wall temperature using the two-phase mixture model. They revealed that the nanofluid and the base fluid have almost the same axial velocity profile, but their thermal profile has a significant change. A better heat transfer enhancement can be achieved at a low Reynolds number $(R e=200)$. They found that the heat transfer coefficient in the developing regions inside a straight tube simulated using mixture model shows a better prediction than the homogeneous model. Karimi et al. [23] performed numerical simulations of nanofluid $\left(\mathrm{Al}_{2} \mathrm{O}_{3}\right.$-water) flow in a double-tube heat exchanger equipped with twisted tape, employing the two-phase mixture model. The results revealed that the use of alumina particles in water augments heat transfer up to $30 \%$ at the cost of increased pressure drop up to $40 \%$. Selvakumar and Dhinakaran [24] performed numerical simulations of nanofluids around a circular cylinder using the two-phase mixture model in the steady flow regime $(10 \leq R e \leq 40)$. They observed that the mixture model predicts higher heat transfer rates compared to the single-phase model.

Numerical studies involving nanofluids that consider a multi-phase approach under natural or mixed convective mode of heat transfer are very few, and they are mainly concerned with the flow of nanofluids in lid-driven cavities [25-29]. Pakravan and Yaghoubi [25] studied numerically the natural convection of nanofluids $\left(\mathrm{Al}_{2} \mathrm{O}_{3}\right.$-water) in a square cavity and compared it with the available experimental data. In their study, the cavity is heated and cooled at constant temperature on two vertical walls while the two horizontal walls are assumed to be adiabatic. A two-phase modeling approach is utilized to consider the nanoparticle migration. It is found that the considered model gives better consistency with experimental measurements relative to the conventional single-phase modelling. They revealed that the Nusselt number $\left(N u_{M}\right)$ of nanofluid for natural convection in a cavity decreases as volume fraction $(\varphi)$ increases and the obtained results are in good agreement with the experimental studies, too. Alinia et al. [26] numerically investigated the mixed convection heat in an inclined cavity with $\mathrm{SiO}_{2}$-water nanofluids. In the cavity, the left and 
right-side walls are at different constant temperatures while the top and bottom side walls are insulated moving lids. A two-phase mixture model is adopted to analyse the thermal behaviour of nanofluids for various enclosure inclination angles ranging from $-60^{\circ}$ to $+60^{\circ}$. The results show that the presence of nanoparticles and their addition in base fluid enhances the heat transfer in the cavity significantly and causes notable changes in the flow pattern. Besides, the effect of inclination angle is more pronounced at higher $R i(\geq 10)$ only. Esfe et al. [27] conducted a 3D-numerical study on free convection in a cubical cavity with porous fins using nanofluid ( $\mathrm{CuO}$-water) as the working fluid. The two-phase mixture model is employed, and the numerical simulations are performed. They have analyzed the result for different Rayleigh numbers $\left(10^{3}-10^{5}\right)$. The numerical results show that at lower Rayleigh number $\left(\sim 10^{3}\right)$ the value of mean Nusselt number is relatively small since conduction dominates over convection. On the other hand, a high Rayleigh number enhances the convection term that becomes more dominant than conduction, which increases the average Nusselt number, since fluid flow irregularity intensifies consequently. Increasing the nanoparticle volume fraction shows an improvement in heat transfer as reported in the aforementioned studies. Garoosi et al. [28] performed numerical simulations considering the steady state mixed convection heat transfer $(0.01 \leq R i \leq 1000)$ of nanofluid (Cu-water, $\mathrm{Al}_{2} \mathrm{O}_{3}$-water, and $\mathrm{TiO}_{2}$-water) using a two-phase mixture model. The authors used a two-sided lid driven cavity with several pairs of heaters and coolers. It is found that at a low $R i$ value, the heat transfer rate increases with the increasing number of heaters and coolers (HACs). On the other hand, at high $R i, N u_{M}$ does not change significantly after a saturated number of HACs. The results reveal that the heat transfer rate increases by reducing the diameter of the nanoparticles and $R i$. Although the thermal conductivity of $\mathrm{Cu}$ is considerably higher than that of $\mathrm{TiO}_{2}$, still the difference in heat transfer is small. Darzi et al. [29] studied the effect of nanofluid on combined convective heat transfer inside a finned enclosure. It is found that adding a small concentration of nanoparticles to base fluid enhances the heat transfer, especially at a low $R i$ value.

Recently, Ebrahimi et al. [30] investigated the heat transfer from longitudinal vortex generators placed inside microchannel heat sinks, with $\mathrm{CuO}$-water and $\mathrm{Al}_{2} \mathrm{O}_{3}$-water nanofluids as the working fluids. Improvement in heat transfer in the ranges 2.55-29.05\% and 9.78-50.64\% was observed for $\mathrm{Al}_{2} \mathrm{O}_{3}$-water and $\mathrm{CuO}$-water nanofluids, respectively. The same research group (Naranjani et al. [31]) further investigated the thermal as well as hydraulic performance of heat sink with corrugated channels using nanofluids. About $22-40 \%$ enhancement in heat transfer was reported while using nanofluids compared to water as coolant. Quite recently, Saieesh and Prasad [32] investigated the laminar forced convective heat transfer from a square cylinder using the Eulerian-Eulerian mixture model considering slip velocity for Reynolds numbers $10-40$ and $\varphi=0-5 \%$. They showed the influence of slip velocity on heat transfer performance of nanofluids. Other recent works dealing with heat transfer with nanofluids include those of Arjun and Rakesh [33] and Sawicka et al. [34].

A review of the archival literature on nanofluid flow around a square cylinder reveals that no study has been made on this topic using the multi-phase modelling approach, in the presence of thermal buoyancy. In addition, no comparison has been made between the two approaches for this flow configuration. In this study, the results obtained from single and multi-phase approaches using SIMPLE algorithm are presented along with the detailed investigations. In particular, the effects of considered parameters (i.e., $\operatorname{Re}, \operatorname{Ri}, \varphi$ ) on the local and global flow and heat transfer characteristics have been presented and discussed. In the present study, nanofluid flow past a hot square cylinder is studied and the resulting heat transfer is compared with that of the base fluid. The temperature field and flow structure around the square cylinder are visualized and presented through the results obtained from numerical simulations performed based on multi-phase modelling. 


\section{Mathematical Formulation}

\subsection{Problem Description and Geometrical Configuration}

A two-dimensional square cylinder (height, D) placed in an unbounded domain is considered as shown in Figure 1a. The cylinder is hot with its surface maintained at a constant temperature $\theta_{w}$ greater than that of the ambient fluid that flows in the positive $x$-direction. The ambient fluid is $\mathrm{Al}_{2} \mathrm{O}_{3}$-water nanofluid flowing with a uniform velocity $\left(U_{0}\right)$ and has a temperature $\theta_{0}$. The thermal buoyancy is considered with the gravity acting opposite to the flow direction and parallel to the flow inlet. The heated cylinder exchanges heat with the nanofluid flowing past its surface, resulting in heat transfer. The boundaries of the computational domain are placed far from the heated cylinder and appropriate boundary conditions are used while performing the calculations. The simulations are carried out for both steady and unsteady flow regimes. The heat transfer taking place from the cylinder can be modelled with appropriate governing equations to predict the flow and thermal field. Since nanofluids contain solid particles dispersed in liquid medium, two kinds of approaches can be followed. One is the single-phase modelling approach and the other is the two-phase modelling approach. In the next section, we describe both the approaches.

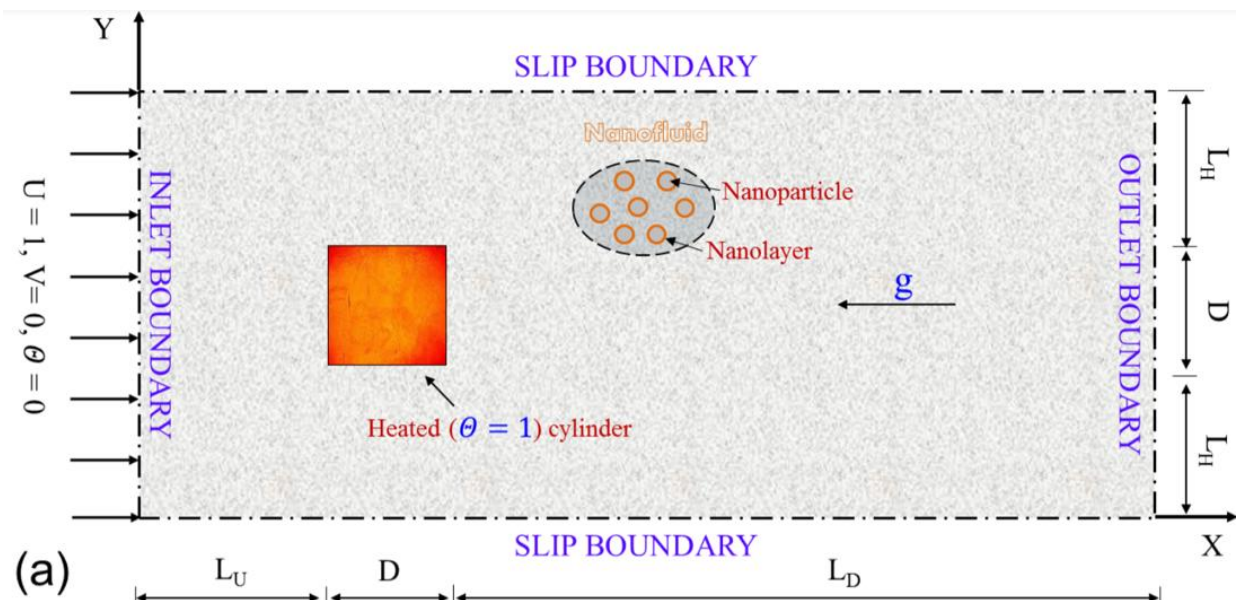

(b)

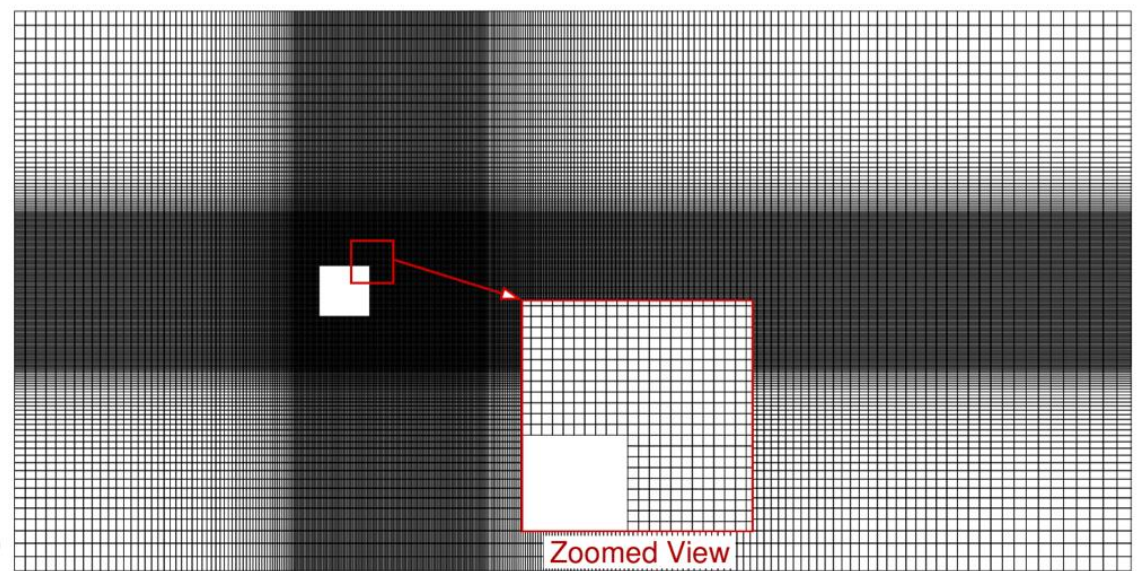

Figure 1. (a) Sketch of the computational domain and its coordinate system along with the imposed boundary conditions. (b) Non-uniform mesh distribution.

\subsection{Governing Equations}

\subsubsection{Single-Phase Model (SPM)}

The single-phase modelling approach assumes that the nanoparticles in the base fluid can be easily fluidized and reach the base fluid velocity. Therefore, the nanofluid is considered a homogeneous fluid. Further, it is assumed that both the liquid and particle 
phases are in thermal equilibrium and move with the same velocity [35]. The governing equations of continuity, momentum, and energy [36] are given as follows:

- Continuity equation:

$$
\nabla \cdot\left(\rho_{n f} \vec{V}_{f}\right)=0
$$

- Momentum equation:

$$
\nabla \cdot\left(\rho_{n} \vec{v}_{f} \vec{v}_{f}\right)=-\nabla P+\nabla \cdot\left(\mu_{n f} \nabla \vec{V}_{f}\right)+\rho_{n f}\left(\theta-\theta_{0}\right) \beta_{n p} \vec{g}
$$

- Energy equation:

$$
\nabla \cdot\left(\rho_{n f} c_{(p, n f)} \vec{V}_{f} \theta\right)=\nabla \cdot\left(K_{n f} \nabla \theta\right)
$$

where, $\vec{V}_{f}, \rho_{n f}, \mu_{n f}, \beta_{n p}, c_{(p, n f)}$, and $K_{n f}$ are the velocity vector, density, viscosity, thermal expansion coefficient, specific heat, and thermal conductivity, respectively. The difference between the solid surface temperature and free-stream average temperature is used as the characteristic temperature difference.

\subsubsection{Nanofluids Modelling}

The volume fraction of nanofluid $(\varphi)$ is the volumetric concentration of the nanoparticles in the nanofluid. The effective properties of nanofluids such as the effective density, viscosity, thermal expansion coefficient, and thermal conductivity are given by

- Effective density:

$$
\rho_{n f}=\phi \rho_{n p}+(1-\phi) \rho_{b f} .
$$

- Effective viscosity (Brinkman [37]):

$$
\mu_{n f}=\mu_{b f} /(1-\phi)^{2.5}
$$

- Effective specific heat (Xuan and Roetzel [38]):

$$
c_{p, n f}=\frac{(1-\phi)\left(\rho c_{p}\right)_{b f}+\phi\left(\rho c_{p}\right)_{n p}}{(1-\phi) \rho_{b f}+\phi \rho_{n p}} .
$$

- Effective thermal conductivity (Xie et al. [39]):

$$
K_{n f}=\left(1+3 \Theta^{\prime} \phi_{T}+\frac{3 \Theta^{\prime 2} \phi_{T}^{2}}{1-\Theta^{\prime} \phi_{T}}\right) K_{b f}, \text { with } \Theta^{\prime}=\frac{\beta_{(n l, b f)}^{\prime}\left[(1+\gamma)^{3}-\frac{\beta_{(n p, n l)}}{\beta_{(b f, n)}^{\prime}}\right]}{(1+\gamma)^{3}+2 \beta_{(n l, b f)}^{\prime} \beta_{(n p, n l)}^{\prime}},
$$

where,

$$
\begin{gathered}
\beta_{(n l, b f)}^{\prime}=\frac{K_{n l}-K_{b f}}{K_{n l}+2 K_{b f}}, \beta_{(n p, n l)}^{\prime}=\frac{K_{n p}-K_{n l}}{K_{n p}+2 K_{n l}}, \beta_{(b f, n l)}^{\prime}=\frac{K_{b f}-K_{n l}}{K_{b f}+2 K_{n l} l^{\prime}}, \\
\phi_{T}=\phi(1+\gamma)^{3}, \gamma=\delta / r_{p}
\end{gathered}
$$

where, $g$ is ratio of the nanolayer thickness $(\delta)$ to the original particle radius $\left(r_{p}\right)$. The nanoparticle diameter $\left(2 r_{p}\right)$ and nanolayer thickness $(\delta)$ are taken as $30 \mathrm{~nm}$ and $2 \mathrm{~nm}$, respectively.

The thermal expansion coefficient of nanofluids can be estimated utilizing the volume fraction of nanoparticles on a weight basis and is given by [40]

$$
(\rho \beta)_{n f}=\left(1-\varphi_{n p}\right)(\rho \beta)_{b f}+\varphi_{n p}(\rho \beta)_{n p} .
$$




\subsubsection{Multi-Phase Model (MPM)}

Unlike the other models (i.e., Eulerian model, VOF model), the mixture model is based on a single fluid but two-phase approach. The phases have their velocity vector (i.e., interpenetrating) closely following the flow, and coupling between them is substantial [26]. In the control volume, primary and secondary phases have their separate volume fractions. The primary phase influences the secondary phase via drag and turbulence, while the secondary phase, in turn, influences the primary phase via a reduction in mean momentum and turbulence. The mixture model is based on the following assumptions [20]: (1) all phases are allocated a single pressure; (2) the secondary phase is assumed to be spherical in shape with uniform particle size and their interactions between different dispersed phases are neglected; (3) the concentrations of the secondary dispersed phases are solved from scalar equations taking into account the correction due to phase slip. It is to be noted that turbulence generation in the secondary phases is not accounted for, nor is the turbulence of the primary phase directly affected by the presence of the secondary phase [41]. Instead of utilizing the governing equations of each phase separately, the continuity, momentum, and energy equations for the mixture are employed and written in the dimensional form as

- Continuity equation:

$$
\nabla \cdot\left(\rho_{m} \vec{V}_{m}\right)=0
$$

- Momentum equation:

$$
\begin{gathered}
\nabla \cdot\left(\rho_{m} \vec{V}_{m} \vec{V}_{m}\right)=-\nabla P_{m}+\nabla \cdot\left(\mu_{m} \nabla \vec{V}_{m}\right)+ \\
\nabla \cdot\left[(1-\phi) \rho_{b f} \vec{V}_{d r, b f} \vec{V}_{d r, b f}+\phi \rho_{n p} \vec{V}_{d r, n p} \vec{V}_{d r, n p}\right]+\rho_{m}\left(T-T_{0}\right) \beta_{m} \vec{g}
\end{gathered}
$$

- Energy equation:

$$
\nabla \cdot\left[\left(\rho_{b f} c_{p, b f}\right)(1-\phi) \vec{V}_{b f} T+\left(\rho_{n p} c_{p, n p}\right) \phi \vec{V}_{n p} T\right]=\nabla \cdot\left(K_{m} \nabla T\right) .
$$

- Volume fraction equation:

In the MPM model, each phase has its own velocity vector field and within a given control volume there exists a certain fraction for each phase. In addition to Equations (9)-(11), the mixture model solves the volume fraction equation for the secondary phase. It then uses an algebraic expression to calculate the relative velocity between the phases

$$
\nabla \cdot\left[(1-\phi) \rho_{n p} \vec{V}_{m}\right]=-\nabla \cdot\left[(1-\phi) \rho_{n p} \vec{V}_{d r, n p}\right]
$$

where, $V_{m}, \rho_{m}, \mu_{m}, K_{m}$, and $P_{m}$ are velocity, density, viscosity, thermal conductivity, and pressure of mixture; $V_{d r, n p}$ and $V_{d r, b f}$ are the drift velocity of nanoparticle and drift velocity of base fluid; $\rho_{b f}$ and $c_{(p, b f)}$ are the density and specific heat of the base fluid; $\rho_{b f}$ and $c_{(p, n f)}$ are the density and specific heat of nanofluids; $\phi$ is the solid volume fraction of the nanoparticles, respectively. The mixture velocity $\vec{V}_{m}$ is determined as follows: $\vec{V}_{m}=$ $\sum_{n p=1}^{n} \frac{\phi_{n p} \rho_{n p} \vec{V}_{n p}}{\rho_{m}}$. In this equation, $\vec{V}_{d r, n p}$ is the drift velocity for the secondary phase and is expressed as, $\vec{V}_{d r, n p}=\vec{V}_{n p}-\vec{V}_{m}$. The velocity of the secondary phase in relation to the primary phase is known as the relative or slip velocity and it is defined as $\vec{V}_{n p, b f}=$ $\vec{V}_{n p}-\vec{V}_{b f}$. The drift velocity is related to the slip velocity as

$$
\vec{V}_{(d r, n p)}=\vec{V}_{(n p, b f)}-\sum_{s=1}^{n} \vec{V}_{(n p, b f)} \frac{\phi_{n p} \rho_{n p}}{\rho_{m}}
$$


The following equations are proposed by Manninen et al. [42] and Schiller [43] to calculate the slip velocity $\vec{V}_{(n p, b f)}$ and drag function $\left(f_{\text {drag }}\right)$, respectively:

$$
\vec{V}_{(n p, b f)}=\frac{\rho_{n p} d_{n p}^{2}}{18 \mu_{b f} f_{d r a g}} \frac{\rho_{n p}-\rho_{m}}{\rho_{n p}} \vec{a}
$$

In the above equation, $R e_{n p}=\frac{d_{n p} \rho_{n p}\left|V_{n p, b f}\right|}{\mu_{m}}$ and the acceleration is given as $\vec{a}=$ $\vec{g}-\left(V_{m} \cdot \nabla\right) V_{m}$. For mixture model calculations, the thermo-physical properties of nanofluids have been taken from their respective models [37-39]. The physical properties of nanoparticle and base fluid are shown in Table 1.

Table 1. Thermo-physical properties of base fluid and nanoparticles at $293 \mathrm{~K}$.

\begin{tabular}{ccc}
\hline Property & Water [21] & $\mathbf{A l}_{\mathbf{2}} \mathbf{O}_{\mathbf{3}}[\mathbf{4 4 , 4 5 ]}$ \\
\hline$\rho\left(\mathrm{Kg} / \mathrm{m}^{3}\right)$ & 998.2 & 3790 \\
\hline$C_{p}(\mathrm{j} / \mathrm{Kg}-\mathrm{K})$ & 4182 & 765 \\
\hline $\mathrm{K}(\mathrm{W} / \mathrm{m}-\mathrm{K})$ & 0.6 & 40 \\
\hline$\mu(\mathrm{Kg} / \mathrm{m}-\mathrm{s})$ & $10.03 \times 10^{-4}$ & - \\
\hline$\beta(1 / \mathrm{K})$ & $2.1 \times 10^{-4}$ & $8.5 \times 10^{-6}$ \\
\hline
\end{tabular}

\subsection{Boundary Conditions}

At the inlet boundary, a uniform flow profile (i.e., $U_{0}=1$, and $\mathrm{V}=0$ ) is assumed. A zero-shear boundary condition is specified along the top and bottom boundaries, (i.e., $\partial U / \partial Y=0$, and $\mathrm{V}=0$ ) of the domain. The right-side boundary is designated as the outlet. This boundary is located sufficiently far downstream from the cylinder, and it is considered as the pressure outlet (i.e., default option in FLUENT, known as 'PRESSURE OUTLET'), which assumes a zero-gauge (static) pressure $(\mathrm{P}=0)$ for the operating pressure. For the velocities, the following boundary conditions are used: $\partial U / \partial Y=0$, and $\partial V / \partial X=0$ [46] The no-slip condition (i.e., $U=0$, and $V=0$ ) is applied on the cylinder surface. For thermal boundary conditions, the top and bottom boundaries of the domain are assumed to be adiabatic, except on the heated cylinder where the non-dimensional temperature (i.e., $\left.\Theta=\left(\Theta-\theta_{0}\right) /\left(\theta_{w}-\theta_{0}\right)\right)$ is unity, and the inlet boundary is kept as $\Theta=0$. The physical properties of the fluid are assumed to be constant except for the density in body force, which varies linearly with temperature (i.e., Boussinesq's hypothesis).

\section{Numerical Details}

\subsection{Grid Sensitivity Analysis and Code Verification}

Sensitivity of the grid to the obtained results is extensively tested. A rectangular domain is employed as shown in Figure 1a. In order to minimise the influence of boundary effects, the top, bottom, inlet, and outlet boundaries are placed sufficiently far away from the square cylinder. As shown in Figure 1b, a structured and non-uniform grid system is used in the entire computational domain. A fine mesh is placed close to the surface of the cylinder. Tests are carried out with four different grid sizes close to the cylinder viz., $\delta=0.001 \mathrm{D}, 0.003 \mathrm{D}$, and 0.01D. Among these, $\delta=0.003 \mathrm{D}$ is found to be the optimum size of the grid close to the cylinder surface. The grids are evenly distributed around the cylinder surface. A non-uniform structured grid, with $\Delta=0.25 \mathrm{D}$, is applied elsewhere. The grids are stretched by smooth transition using different bias factors i.e., (growth rate) $\times$ (number of divisions $^{-1}$ ). Table 2 summarizes the effect of grid size and downstream length $\left(L_{D}\right)$. Influence of $L_{D}$ on the drag coefficient $\left(C_{D}\right)$ and mean Nusselt number $\left(N u_{M}\right)$ of the cylinder are tested for four distinct values of $L_{D}=10 \mathrm{D}, 15 \mathrm{D}, 20 \mathrm{D}$, and $25 \mathrm{D}$ at $R i=0$ and 1. Finally, as mentioned in Table 2, at $L_{D}=15 \mathrm{D}$ and grid size of $244 \times 134$, grid 
point are found to be the best choice as they predict the flow features best while incurring comparatively less computational time.

Table 2. Grid sensitivity and downstream length $\left(L_{D}\right)$ dependence test on drag coefficient $\left(C_{D}\right)$ and Nusselt number $\left(N u_{M}\right)$ of cylinder at $R e=50$ and volume fraction, $\varphi=5 \%$.

\begin{tabular}{|c|c|c|c|c|c|}
\hline \multirow{2}{*}{$L_{D} / \mathrm{D}$} & \multirow{2}{*}{$\begin{array}{c}\text { Grid Size } \\
(\mathrm{m} \times \mathrm{n})\end{array}$} & \multicolumn{2}{|c|}{$R i=0$} & \multicolumn{2}{|c|}{$R i=1$} \\
\hline & & $C_{D}$ & $N u_{M}$ & $C_{D}$ & $N u_{M}$ \\
\hline \multirow{3}{*}{10} & $172 \times 102$ & 1.896 & 8.3245 & 7.584 & 9.8541 \\
\hline & $194 \times 124$ & 1.8152 & 8.1251 & 7.4879 & 9.8574 \\
\hline & $260 \times 190$ & 1.7548 & 7.8951 & 7.3215 & 9.5411 \\
\hline \multirow{3}{*}{15 * } & $222 \times 112$ & 1.7984 & 7.4614 & 5.6412 & 9.2448 \\
\hline & $244 \times 134$ * & 1.7843 & 7.4566 & 5.6332 & 9.2258 \\
\hline & $310 \times 200$ & 1.7843 & 7.4564 & 5.6332 & 9.2256 \\
\hline \multirow{3}{*}{20} & $272 \times 122$ & 1.7784 & 7.5842 & 5.6311 & 9.2258 \\
\hline & $294 \times 144$ & 1.7842 & 7.4566 & 5.6332 & 9.2258 \\
\hline & $360 \times 210$ & 1.7843 & 7.4548 & 5.6422 & 9.2255 \\
\hline \multirow{3}{*}{25} & $322 \times 132$ & 1.7821 & 7.4667 & 5.6411 & 9.2287 \\
\hline & $344 \times 154$ & 1.7833 & 7.4545 & 5.6612 & 9.2255 \\
\hline & $410 \times 220$ & 1.7844 & 7.4566 & 5.6332 & 9.2258 \\
\hline
\end{tabular}

${ }^{*}$ Mesh and downstream length $\left(L_{D}\right)$ used in this study.

\subsection{Numerical Method}

The governing equations of fluid flow and heat transfer, namely Equations (1)-(3) (for single-phase simulations), and Equations (10)-(12) (for two-phase simulations) are solved using the commercial CFD software-ANSYS FLUENT (service pack; 15.0.7) [47]. The QUICK scheme is utilized for discretizing the convection terms, while the second-order central difference scheme is used for the diffusion terms. The SIMPLE algorithm is used for pressure-velocity coupling. It is found that the SIMPLE algorithm shows good agreement between experimental and numerical results [23]. The node-based method is adopted to find gradients on the mesh surface. Then, 2D numerical simulations are carried out for an isothermally heated cylinder immersed in nanofluid when both the imposed flow and the buoyancy induced motion are in the same direction, i.e., the so-called buoyancy aiding configuration. In the Boussinesq approximation context, the suitable forms of the momentum and thermal energy equations for the mixture model are solved numerically. In all the simulations, solutions are assumed to be converged when the residual in each cell dropped to $10^{-6}$.

\section{Results and Discussions}

Mixed convective heat transfer from a square cylinder in a uniform flow, with nanofluids as working fluid, is investigated for the following operating parameters:

- $\quad$ Reynolds number $(R e)=10,30,50,80,100$, and 150 .

- $\quad$ Richardson number $(R i)=0,0.5$, and 1 .

- Volume fraction of nanoparticles $(\varphi)=0,1 \%, 3 \%$, and $5 \%$.

\subsection{Fluid Flow Characteristics}

\subsubsection{Flow Patterns}

The time evolution of lift coefficient, streamlines, and instantaneous vorticity contours in the vicinity of the cylinder are shown in Figure 2a-c for $R e=10,30,50,80$, and 100 at $R i=0$. From the time evolution of lift coefficient shown in Figure $2 \mathrm{a}$, it is observed that flow is steady for $R e<50$, while it has turned unsteady at $R e=50$. The critical Reynolds 
number $\left(R e_{c r}\right)$ for wake instability is observed to be equal to $44.7,45,46,47 \pm 2$, and 49.5 in the work of Park and Yang [48], Saha et al. [49], Jiang et al. [50], Sohankar et al. [51], and Abdelhamid et al. 2021 [52], respectively. It can be seen in Figure $2 b$ that the flow separates at the leading edge of the cylinder at $R e=10$. Consequently, a separation bubble (steady recirculating region) consisting of twin symmetric vortices forms at the leeward side of the cylinder. This separation bubble increases in size with $R e$, and the flow remains steady at $\operatorname{Re}=30$ [53]. At a higher Reynolds number, i.e., $\operatorname{Re} \sim 80$, the flow separates at the leading edge of the cylinder and reattaches at a short distance downstream, thus forming a small recirculation region on the side faces of the cylinder. Overall, distinct flow patterns such as steady flow separation at the trailing edge with a separation bubble at the leeward side, flow separation at the trailing edge with vortex shedding, separation at the leading edge and reattachment on the sides of the cylinder, and separation at the leading edge with no reattachment, can be identified, as seen in subplots $(i-v)$ of Figure $2 b$.

(a) Lift coefficient

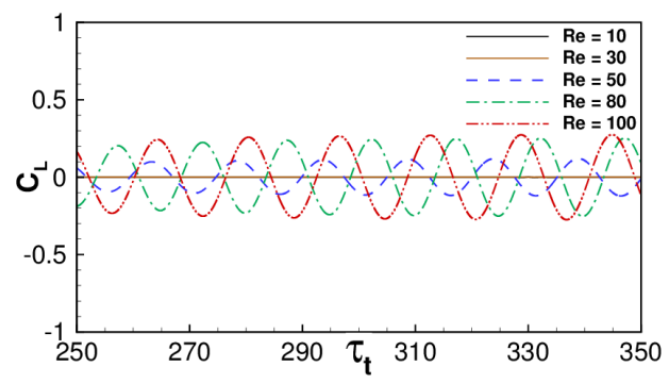

(b) Streamlines
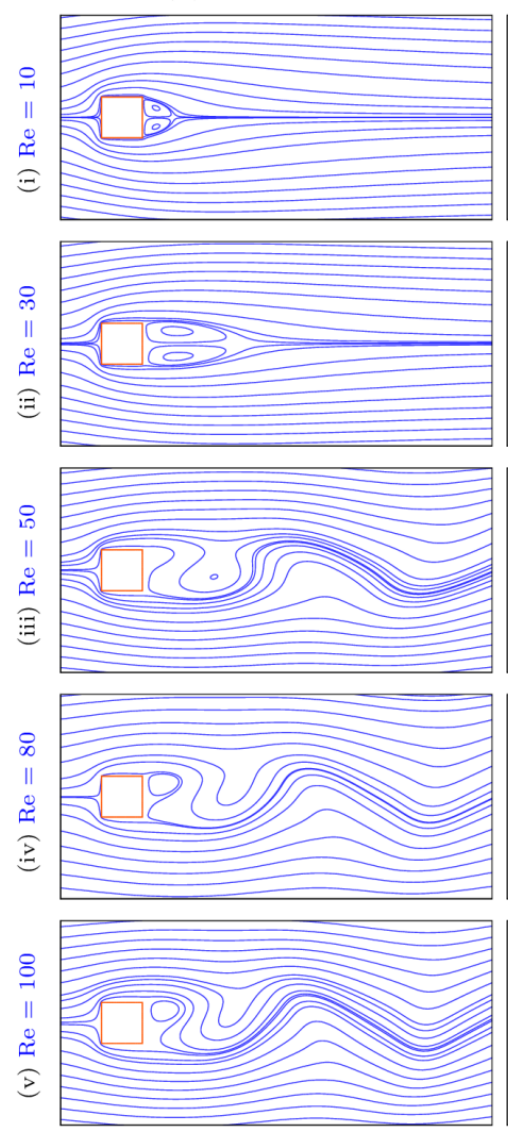

(c) Vorticity Contours
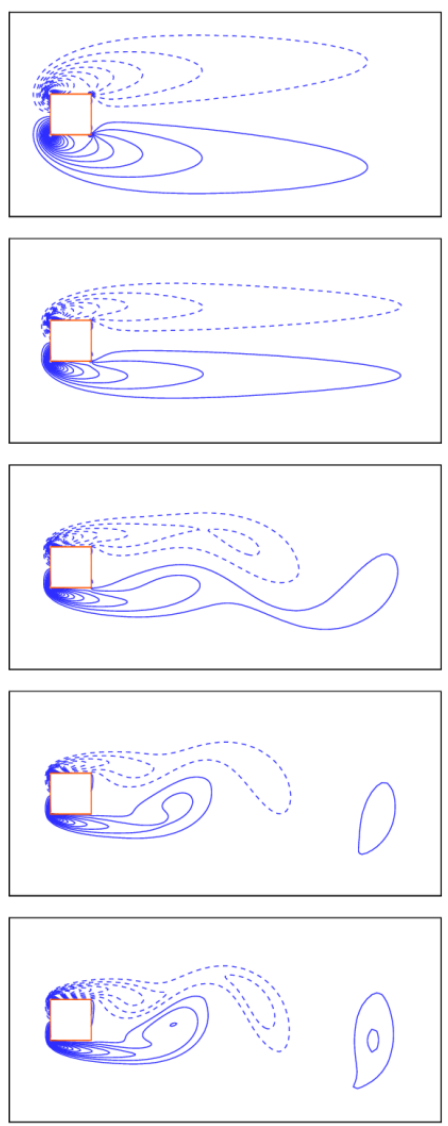

Figure 2. (a) Time evolution of lift coefficient $\left(\mathrm{C}_{\mathrm{L}}\right)$, (b) instantaneous vorticity contours, and (c) streamlines for different values of $\operatorname{Re}$ at $R i=0$ and $\varphi=5 \%$. 
The vorticity contours are presented in Figure $2 \mathrm{c}$ to gain further insights into fluid flow, especially near the cylinder. At $R e=50$, the vortices in the separation bubble start to separate alternately from the trailing edge of the square cylinder. As a result, the positive (i.e., anticlockwise rotation of the fluid remarked by solid lines) and negative vortices (i.e., clockwise rotation of the fluid remarked by dashed lines) grow periodically and start to shed from the cylinder and move downstream due to the Bènard-von Kàrmàn instability phenomena. This phenomenon is referred to as vortex shedding, which can be clearly seen in subplot (iii) of Figure 2c.

Time-averaged streamlines obtained by averaging the stream function during a shedding cycle are presented in Figures 3 and 4 . The recirculation bubble at the leeward side of the cylinder increases with $R e$ when $R i$ is maintained constant (see, subplots (i-iv) of Figure $3 a, b)$. The opposite trend is observed with increasing $R i$ when $R e$ is maintained constant (see, subplots (i-iii) of Figure 3a,b). This is most likely because buoyancy increases the velocity gradient at the cylinder surface and reduces the pressure over the surface of the cylinder that affects the size of the recirculation bubble. The density of the velocity vectors is high at $R i=1$ compared to $R i=0$ due to aiding buoyancy as seen in Figure $5 \mathrm{~b}$. Therefore, at any fixed value of $R e$, the wake length at $R i=0$ would be higher than that at $R i=0.5$ and 1 . Similar findings are also reported by Sharma et al. [54] in their study on the mixed convection heat transfer from a square cylinder under thermal buoyancy at low Re values.

Further, the downstream stretching of vorticity contours increases with $R e$ at a fixed value of $R i$. The magnitude of the vorticity near the surface of the cylinder increases with an increase in $R e$ and/or $R i$, as seen in Figure 6a,b. Further, the effects of thermal buoyancy on heat transfer are discussed in Section 5.2.1. Comparison of the results between single-phase and multi-phase approaches is shown through streamline plots and vorticity contours in Figure 7I,II at different values of $R e$ and $R i$. It is observed that the wake and vorticity patterns show qualitatively similar trends for both the approaches for the considered parameters.

\subsubsection{Time-Averaged Pressure Coefficient}

The variation of time-averaged pressure coefficient $\left(C_{P}\right)$ on the face of the cylinder is presented for $R e=10,50,80$, and 100 at $R i=0,0.5$, and 1.0 for nanoparticle volume fraction $\varphi=0 \%$ and $5 \%$ in Figure $8 \mathrm{a}-\mathrm{f}$. The maximum value of $C_{P}$ is observed (near the front stagnation point) at the windward side (i.e., $\mathrm{CD}$ ) of the cylinder compared to other surfaces (i.e., $\mathrm{AB}, \mathrm{BC}$, and $\mathrm{DA}$ ). This is consistent with the results of Gupta et al. [55] who investigated the flow and heat transfer from a semi-circular cylinder in a confined domain in the presence of buoyancy. The difference in magnitude of $C_{P}$ on the windward (CD) and leeward $(\mathrm{AB})$ surfaces decrease with $R e$. As seen in subplots $(\mathrm{a}-\mathrm{c})$ of Figure 8, the pressure coefficient increases with $R i$ at a fixed value of $R e$. Still, $C_{P}$ has no appreciable change with an increase of $\varphi$ value in both buoyancy and non-buoyancy cases as observed in subplots $(\mathrm{d}-\mathrm{f})$ of Figure 8. Overall, $C_{P}$ varies with $R e$ and $R i$ regardless of the $\varphi$ variation. 
(a) $R i=0$
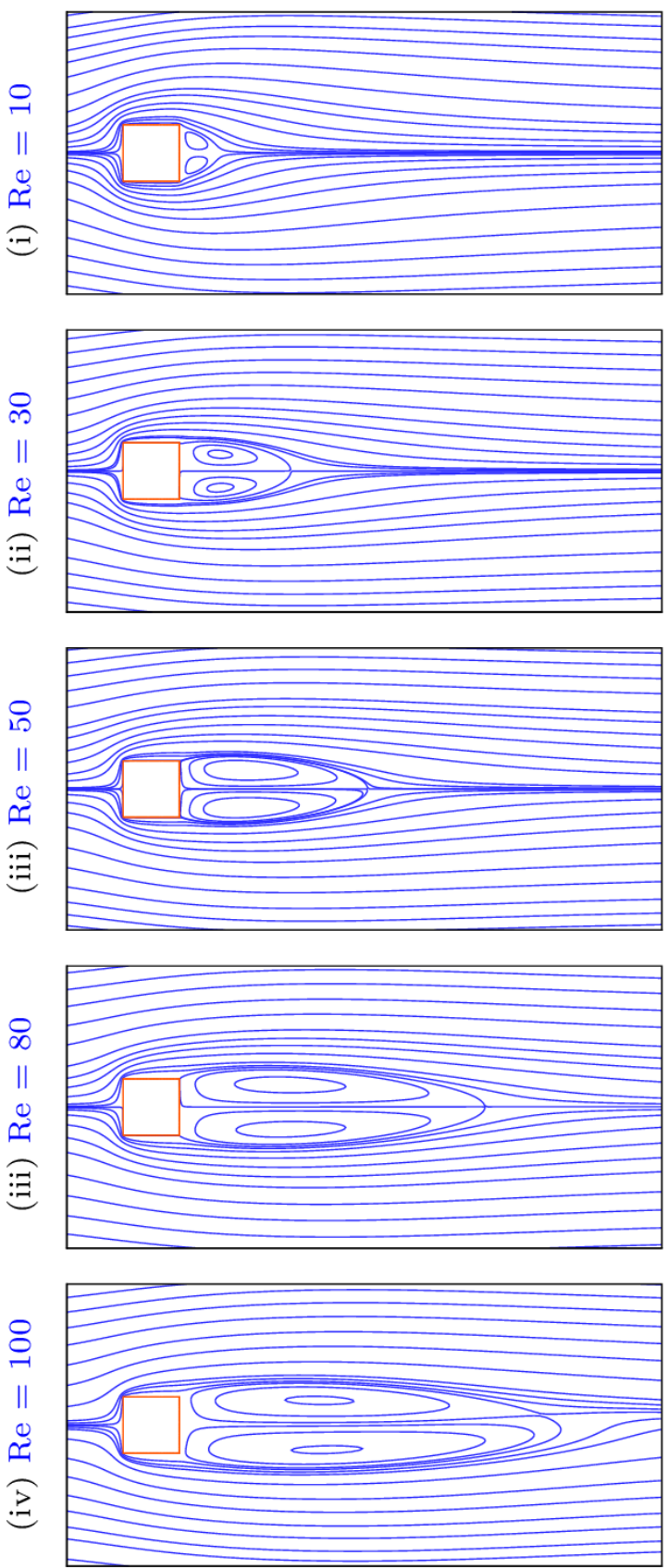

(b) $R i=1$
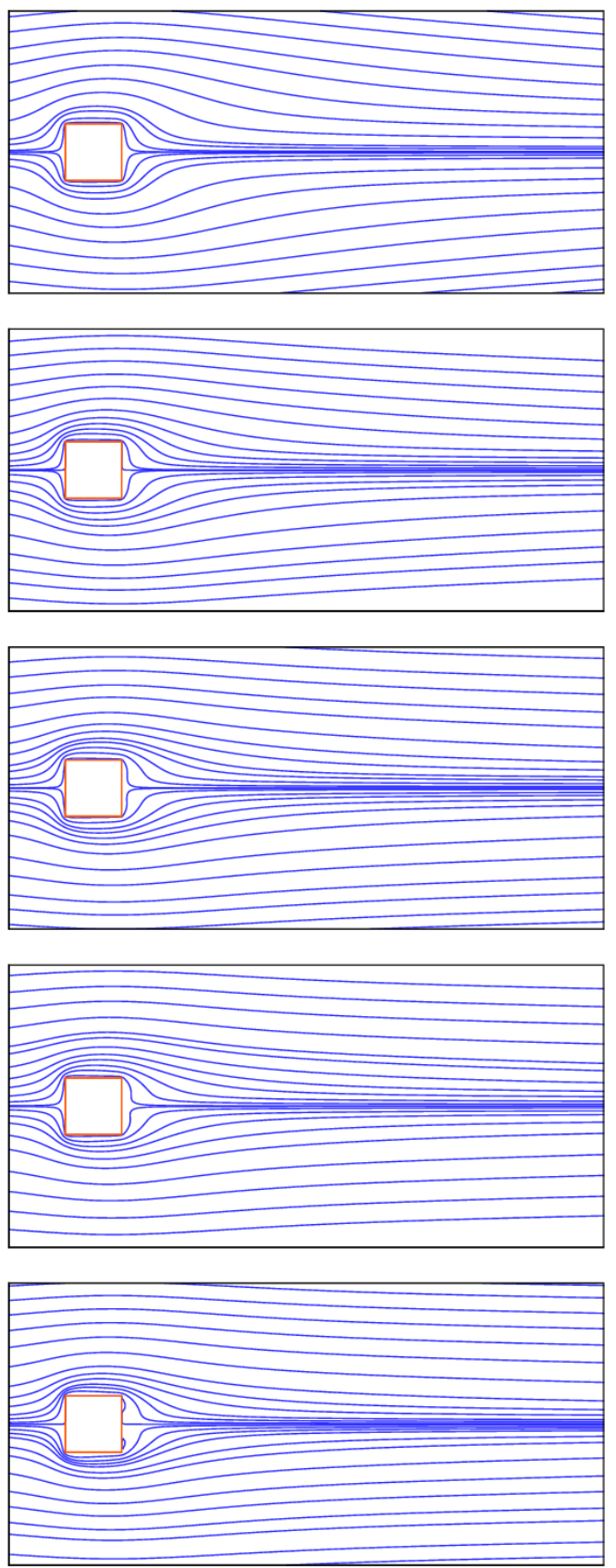

Figure 3. Time-averaged streamlines for different values of $\operatorname{Re}$ at $\varphi=5 \%$ for (a) $R i=0$ and (b) $R i=1$. 


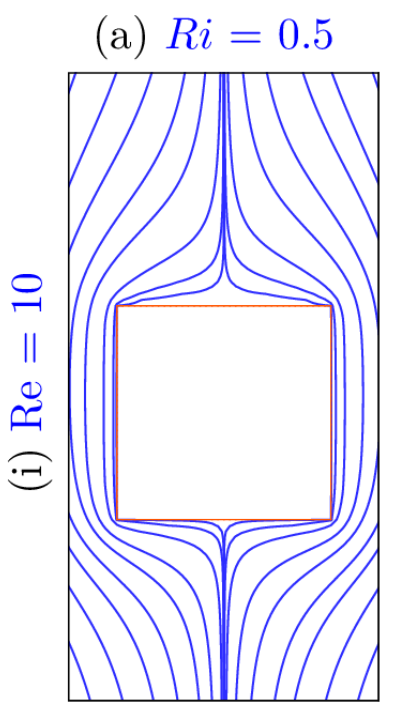

(b) $R i=1$
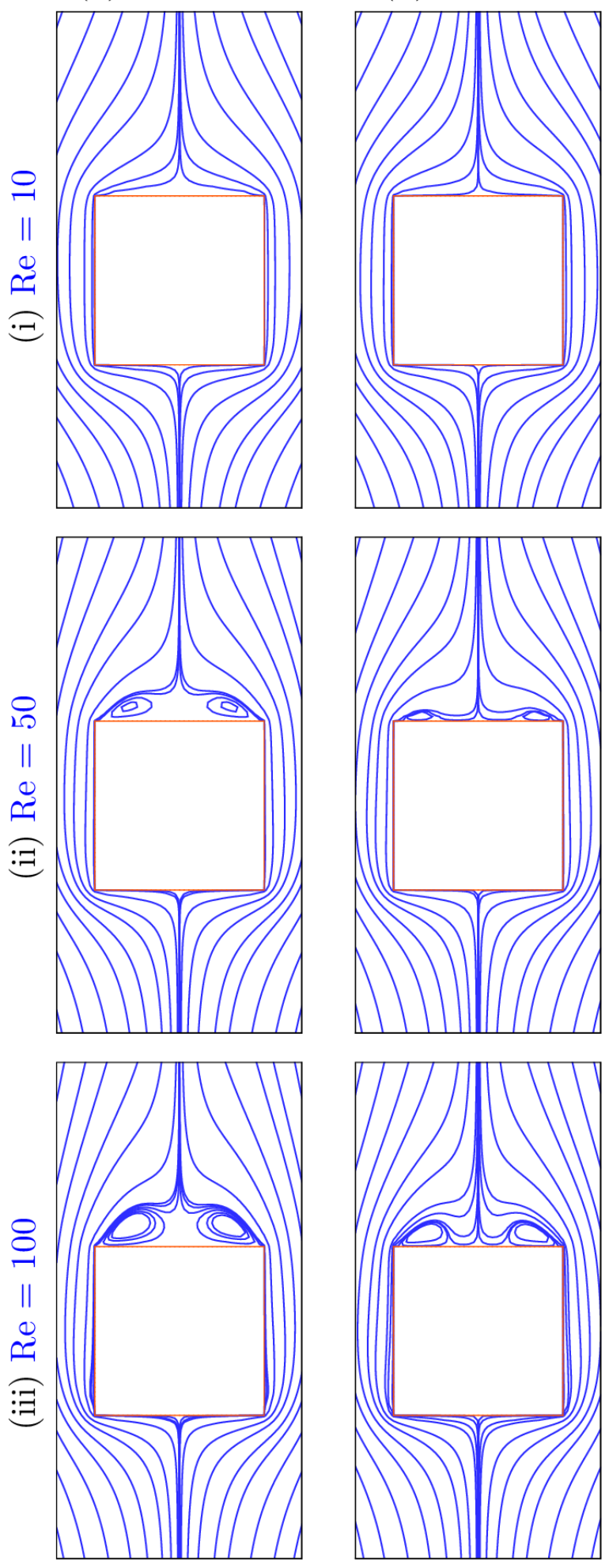

Figure 4. Time-averaged streamlines for different values of $\operatorname{Re}$ at $\varphi=5 \%$ for (a) $R i=0.5$ and (b) $R i=1$. 
(a) $R i=0$
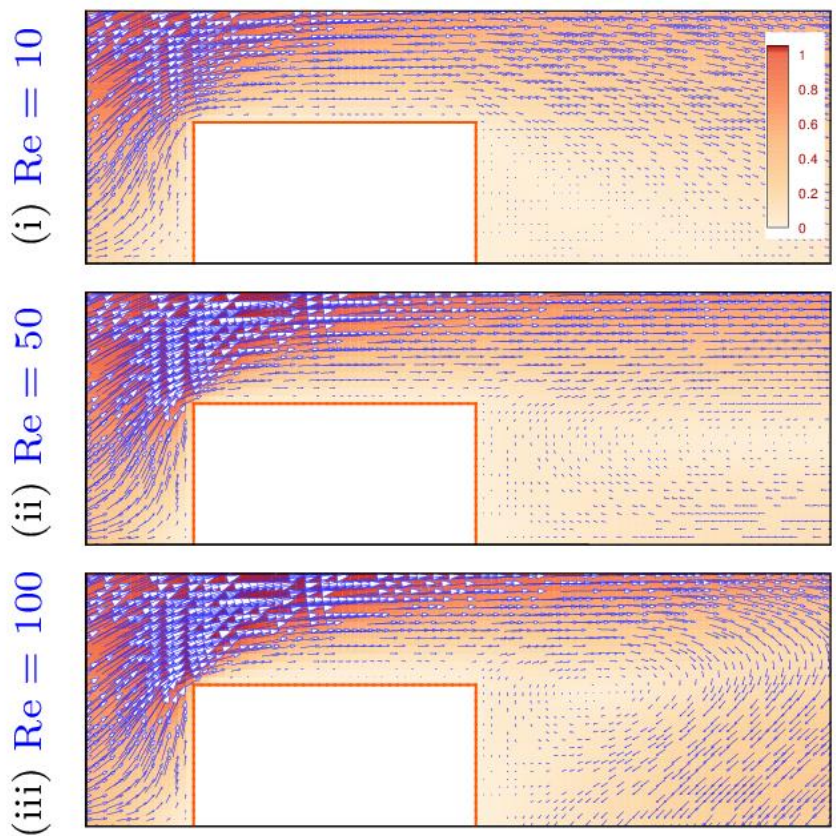

(b) $R i=1$
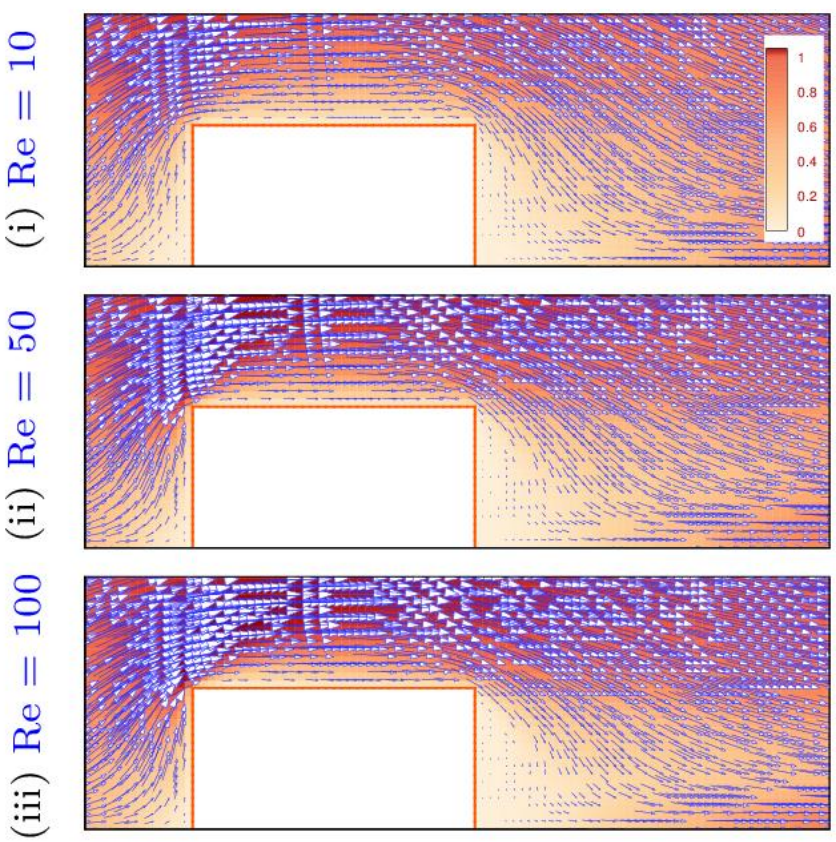

Figure 5. Velocity vectors and contours of velocity above a horizontal plane passing through the centre of the cylinder for different values of $\operatorname{Re}$ and $R i$ at $\varphi=5 \%$ : (a) $R i=0$ and $(\mathbf{b}) \operatorname{Ri}=1$. 
(a) $R i=0$
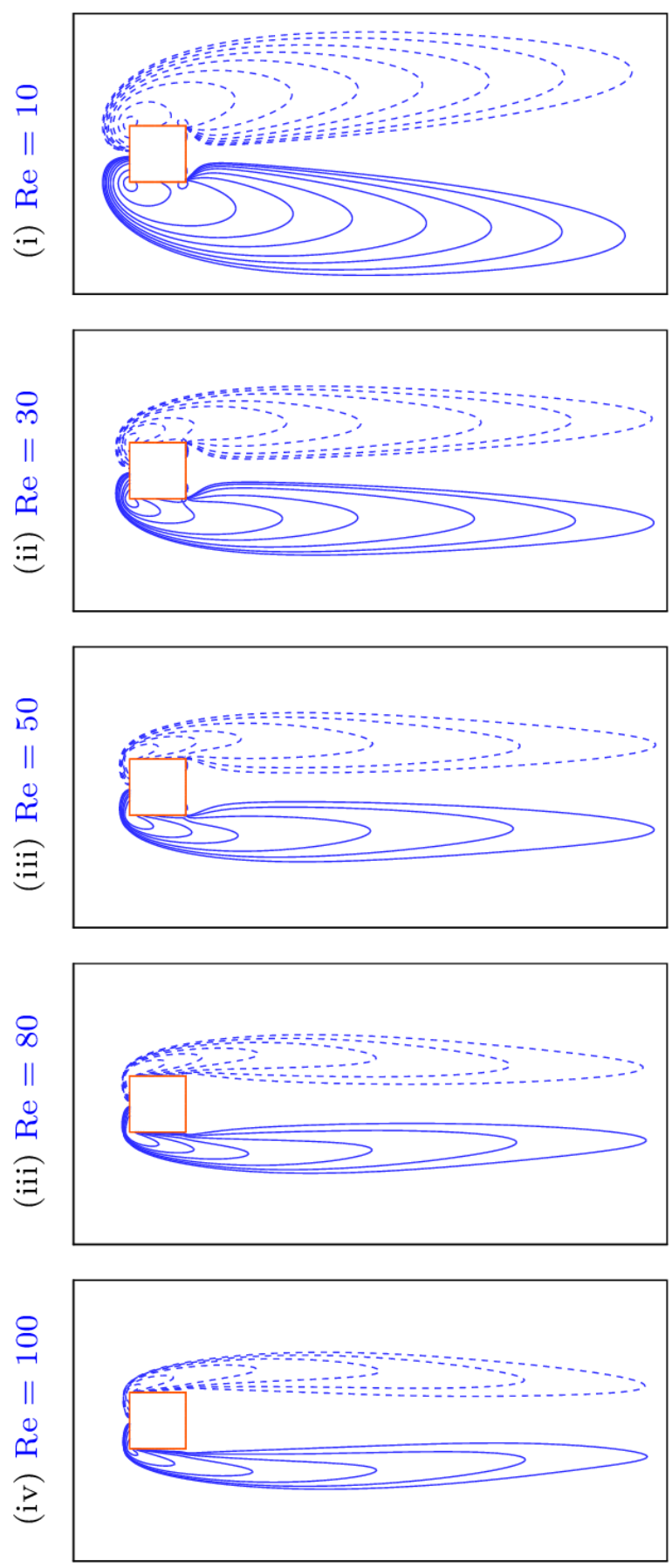

(b) $R i=1$
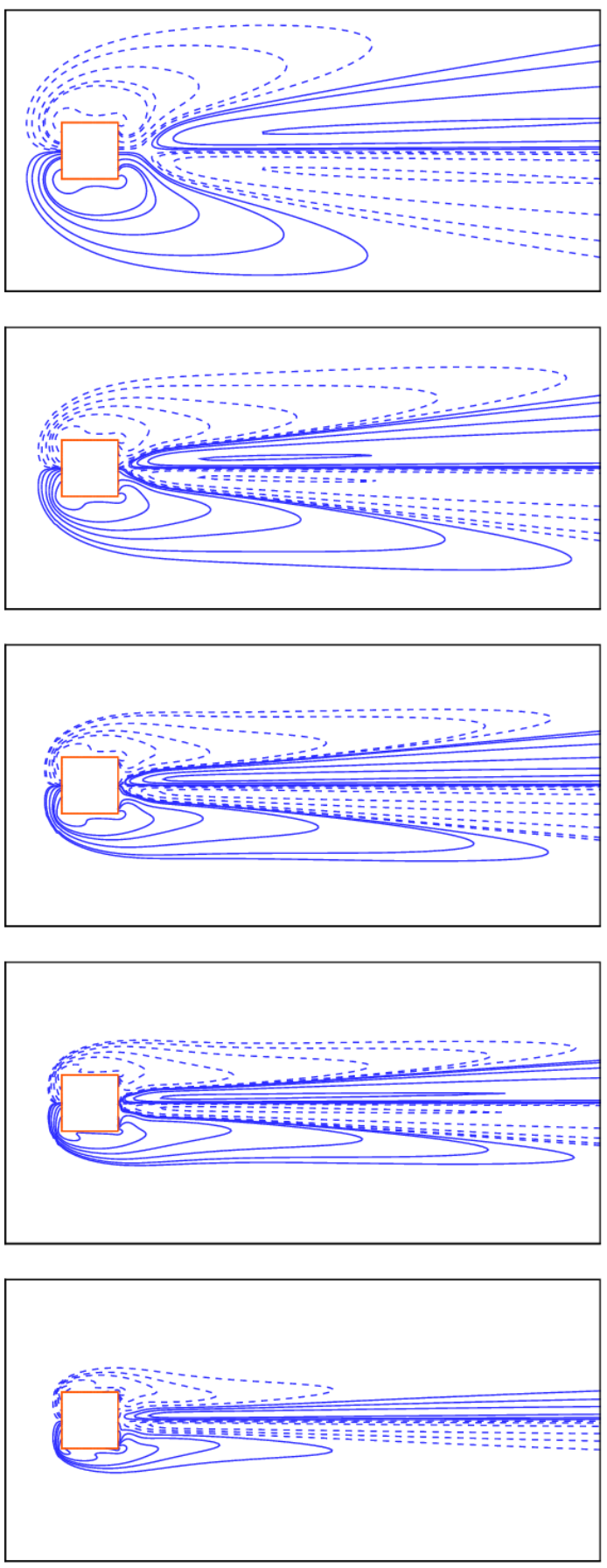

Figure 6. Time-averaged vorticity contours for different values of $\operatorname{Re}$ at $\varphi=5 \%$ and $R i$; (a) 0 and (b) 1 . 
(I) Streamlines Contours
(a) $R i=0$
(b) $R i=1$
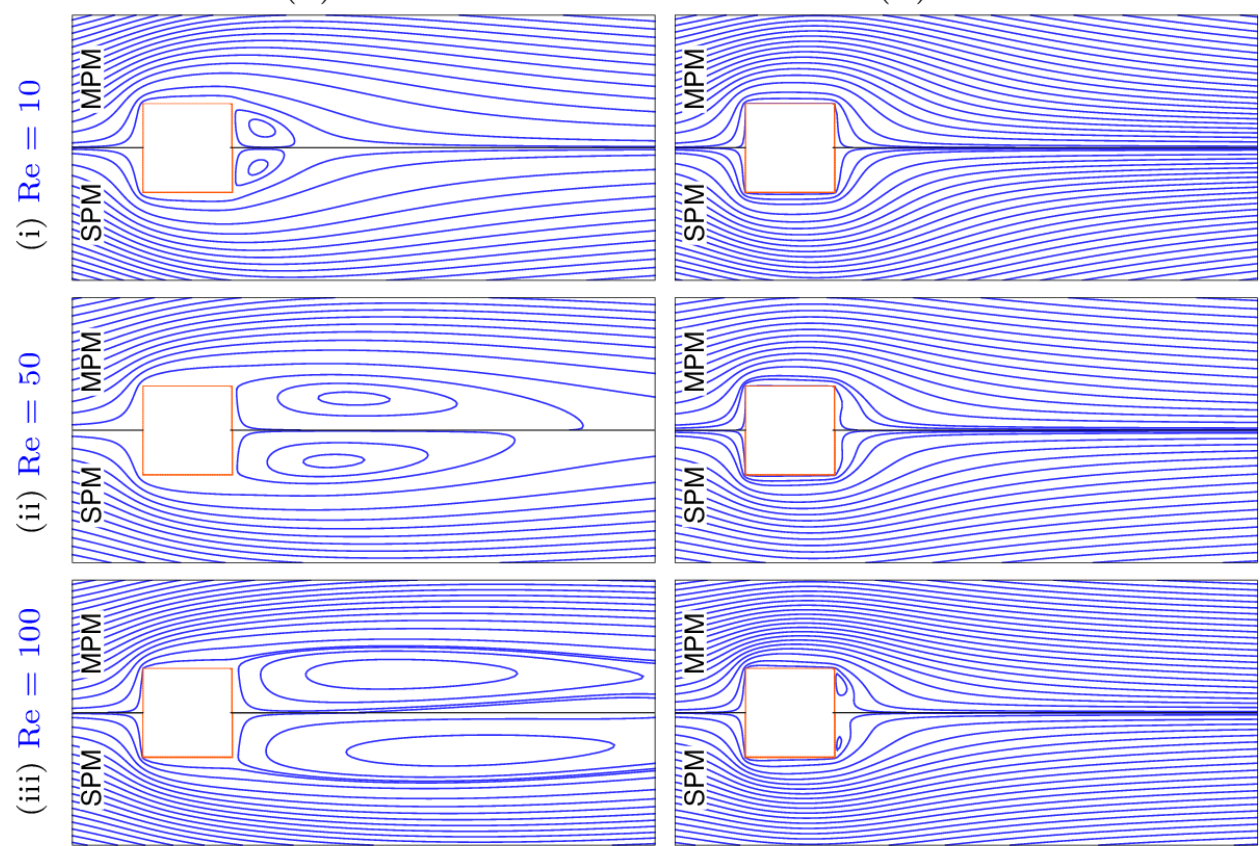

(II) Vorticity Contours

(a) $R i=0$
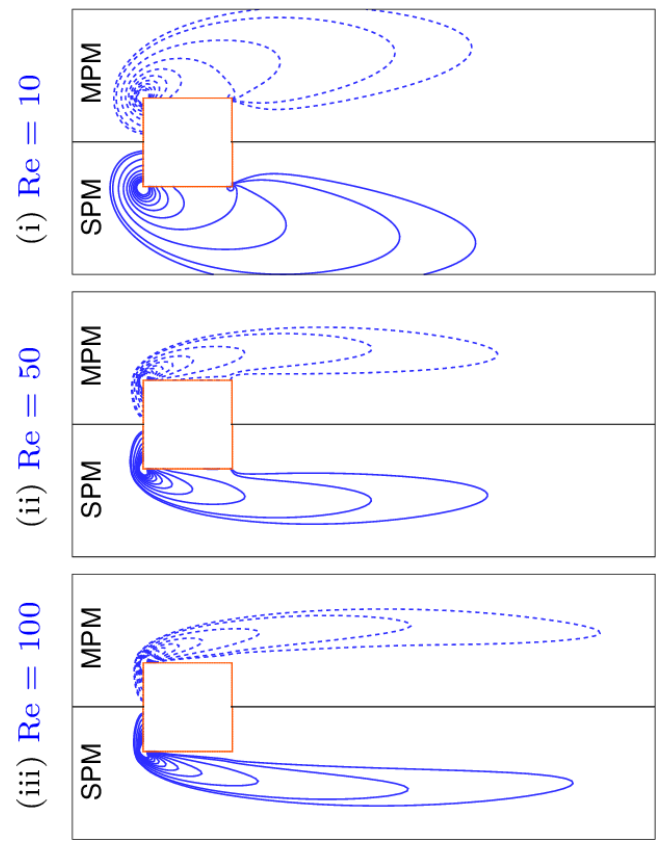

(b) $R i=1$
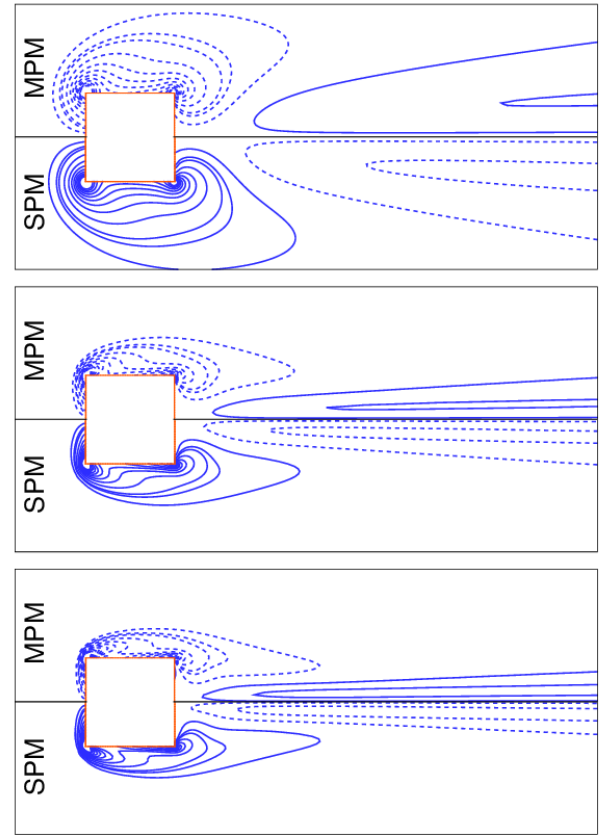

Figure 7. Comparison of single-phase and multi-phase modelling approach with (a) streamlines and (b) vorticity contours, for different values of $\operatorname{Re}$ and $R i$ at $\varphi=5 \%$. 
(a) $R i=0$

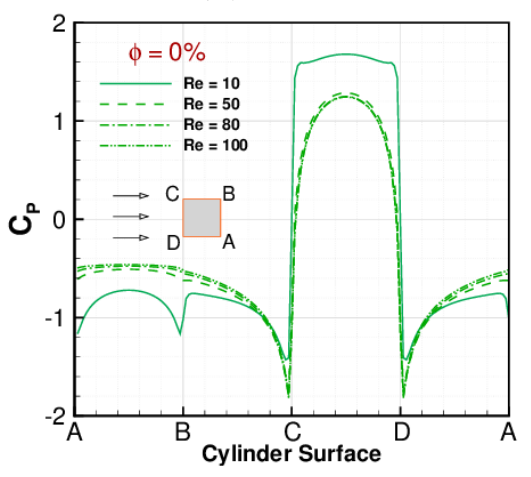

(d) $R i=0$

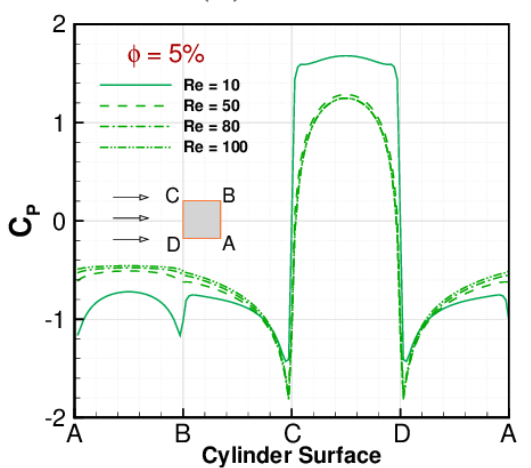

(b) $R i=0.5$

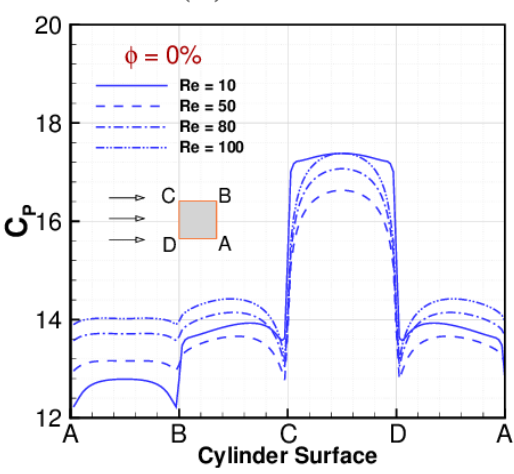

(e) $R i=0.5$

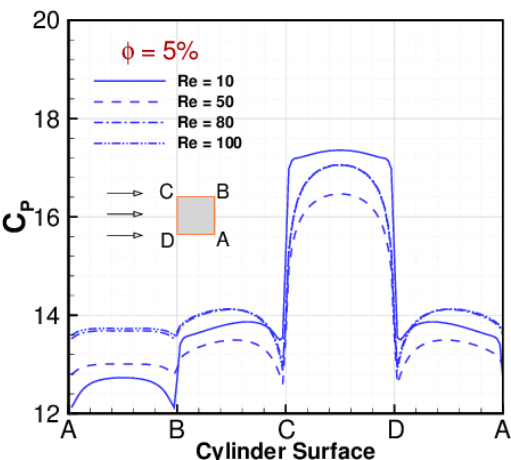

(c) $R i=1.0$

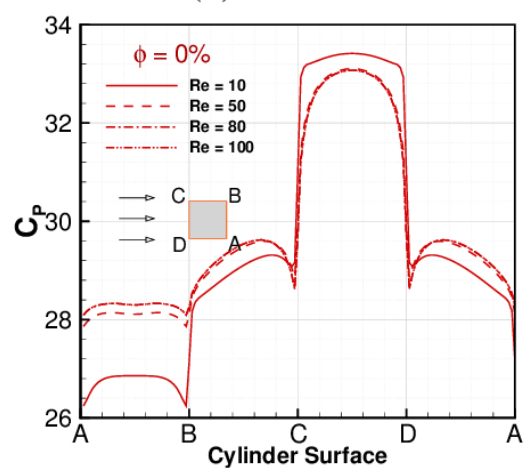

(f) $R i=1.0$

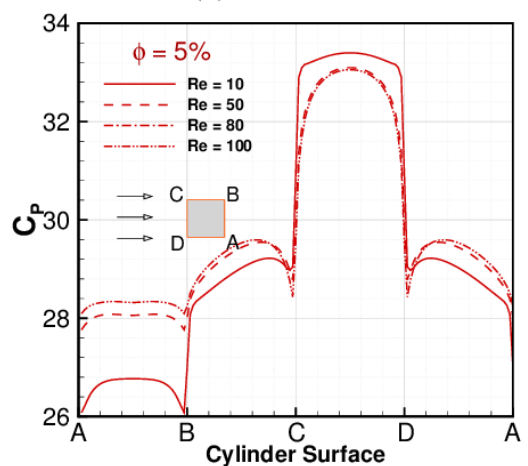

Figure 8. Distribution of pressure coefficient $\left(C_{P}\right)$ on the surface of the heated cylinder for different values of $\operatorname{Re}, \mathrm{Ri}$, and $\varphi$.

\subsubsection{Time-Averaged Drag Coefficients}

The variation of time-averaged drag coefficient for the flow past a square cylinder is presented as a function of $R e$ for different values of $\varphi$ at $R i=0,0.5$, and 1, in Figure 9a-c. The drag coefficient $\left(C_{D}\right)$ decreases with an increase of $R e$ from 10 to 150 , as can be seen in Figure 9a. It is well documented that at $R i=0$, in the steady flow regime, $C_{D}$ is mostly due to viscous drag and it decreases with an increase in $R e$. In the unsteady vortex shedding regime, as eddies are continuously shed from the cylinder, $C_{D}$ is mainly due to pressure drag. A slight increment in $C_{D}$ is observed with an increase in Re from 100 to 150, as seen in the zoomed view in subplot (a) of Figure 9. This decrement of $C_{D}$ with Re in steady flow regime is significantly high compared to unsteady flow regime. For lower values (i.e., $10 \leq R e \leq 50)$ of $R e$ at $R i=0, C_{D}$ increases with an increase in the nanoparticles volume fraction $(\varphi)$ in base fluid. This is noticeable at $R e=10$ in the zoomed view of subplot (a) of Figure 9. It is noted that the effective viscosity $\left(\mu_{n f}\right)$ increases with $\varphi$, and this leads to an increase in viscous drag force that exerts a more retarding force to the shear layers and consequently the magnitude of $C_{D}$ is increased. For higher Re values ( $\left.>50\right)$, effects of an increment of $\varphi$ on $C_{D}$ is found to be negligible. Similarly, at higher values of $R i$ (i.e., 0.5 and 1), effects of $\varphi$ on $C_{D}$ are not significant (see subplots (b,c) of Figure 9). It can also be concluded from Figure $9 \mathrm{a}-\mathrm{c}$ that $C_{D}$ increases with $R i$ in the presence of buoyancy as more forces are exerted on the cylinder. The findings are also consistent with the literature reported for the mixed convection heat transfer from a circular cylinder [56]. 

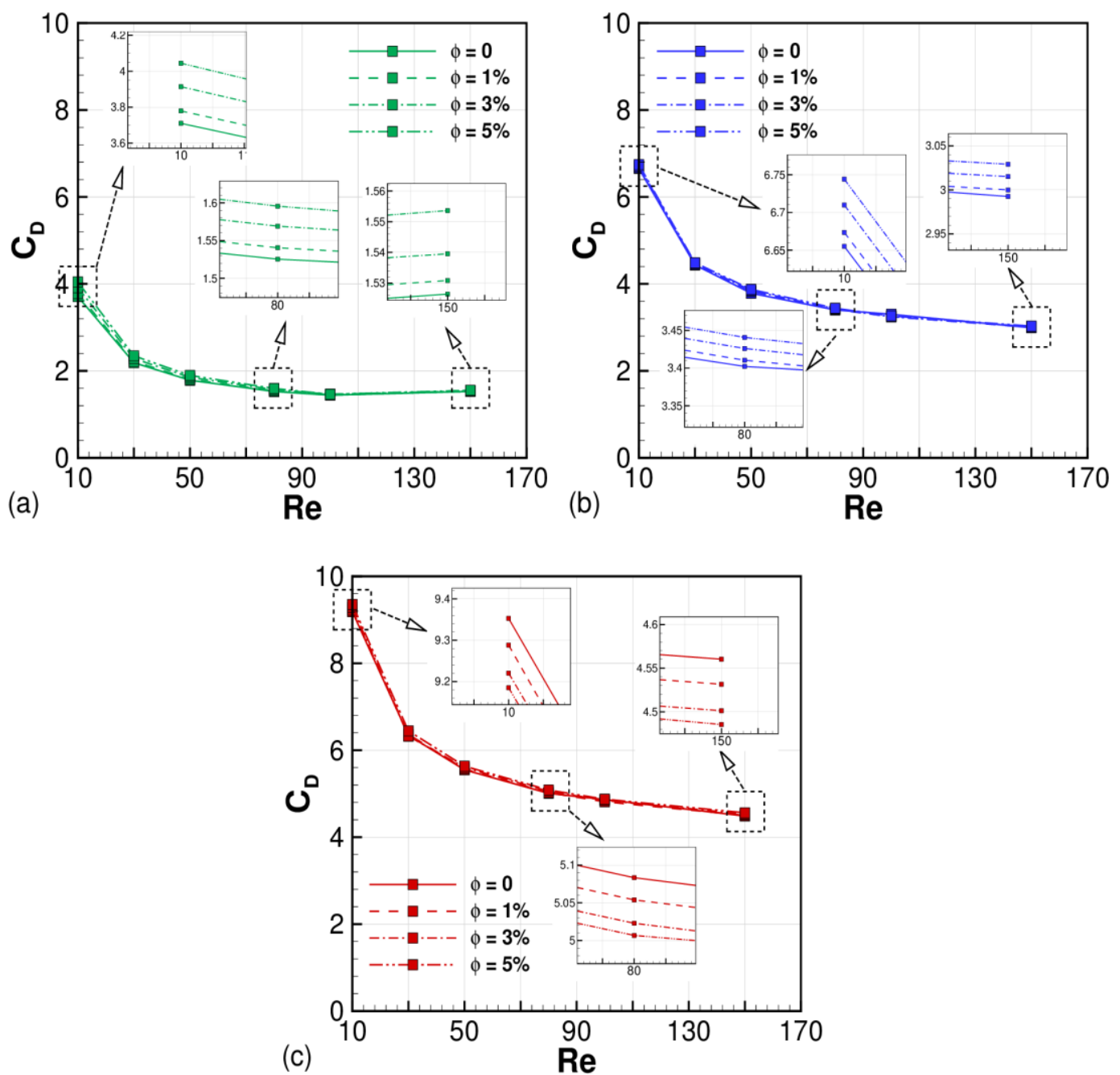

Figure 9. Drag coefficient $\left(C_{D}\right)$ as a function of $\operatorname{Re}$ for different values of $\varphi$ at $\operatorname{Ri}$; (a) $0,(\mathbf{b}) 0.5$, and (c) 1.0.

\subsection{Heat Transfer Characteristics \\ 5.2.1. Isotherms}

Contours of isotherms around the heated square cylinder are shown in Figures 10-12 for different values of $R e, R i, \varphi$ where a comparison between single-phase and multi-phase models are also shown. Figure 10a-c shows the isotherms at $R i=0,0.5$, and 1 when $R e=10$, 50 , and 100. At $R i=0$, when $R e$ is increased from 10 to 100 , the clustering of the isotherms increases around the cylinder. One can understand that at lower values of $R e$ heat transfer occurs mainly due to diffusion process and at higher values of $R e$ the thermal boundary layer spreads along the flow direction due to the dominance of convective transport (see, Figure 10a). Under aiding buoyancy conditions ( $R i=0.5$ and 1$)$ within the same Re range, clustering and lateral thinning of the thermal boundary layer can be seen in the wake region towards the downstream direction as $R i$ increases from 0.5 to 1 . This clustering of the thermal boundary layer on the windward side is highest, followed by the top/bottom face and then the rear face of the cylinder and accordingly heat transfer rate changes along the surface (see, Section 5.2.2). The edging of the thermal boundary layer along the centre line and towards the downstream direction increases with increasing value of $R i$ and/or $R e$ as observed in Figure 10b,c.

In Figure 11a,b, a comparison between the isotherms for base fluid $(\varphi=0 \%)$ and the nanofluid $(\varphi=5 \%)$ is presented at $R i=0$ and 1 . In the subplot, the upper half of the isotherms is for nanofluid while the lower half shows the results for base fluid. From the 
figure, it is observed that the effect of $\varphi$ on the thickness of a thermal boundary layer is more noticeable only at a lower value of $\operatorname{Re}$ (see, subplot (i) of Figure 11a,b). It is known that adding nanoparticles to base fluid increases the effective viscosity $\left(\mu_{n f}\right)$ and the effective thermal conductivity $\left(K_{n f}\right)$ of fluid. Consequently, an increase in $\mu_{n f}$ reduces the convection effect while an increase in $K_{n f}$ enhances the heat transfer. Still, fluid momentum produced due to the buoyancy and inertial forces are high enough to overcome the decrement of convection induced by viscosity. Furthermore, minor changes are found on the thermal boundary layer with increment in $\varphi$ at higher values of $R i$ and $R e$, as seen in subplots (ii,iii) of Figure 11b. A comparison of the isotherms for single and multi-phase models are presented in Figure 12a,b. A significant change in isotherm patterns can be observed at a lower value of $\operatorname{Re}$ only with the change in $R i$ (see, subplot (i) of Figure 12a,b).

(a) $R i=0$
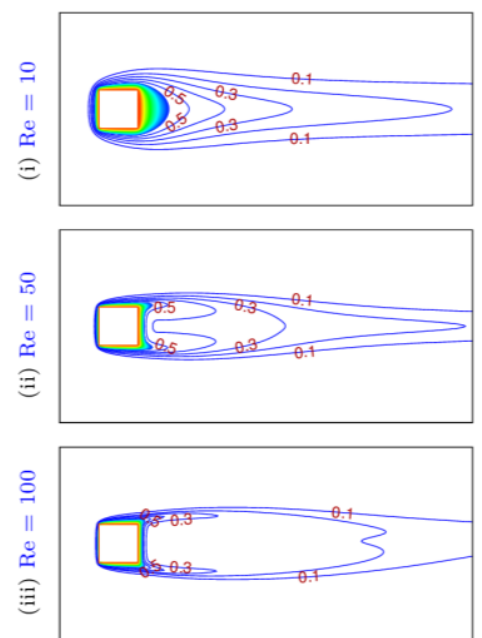

(b) $R i=0.5$
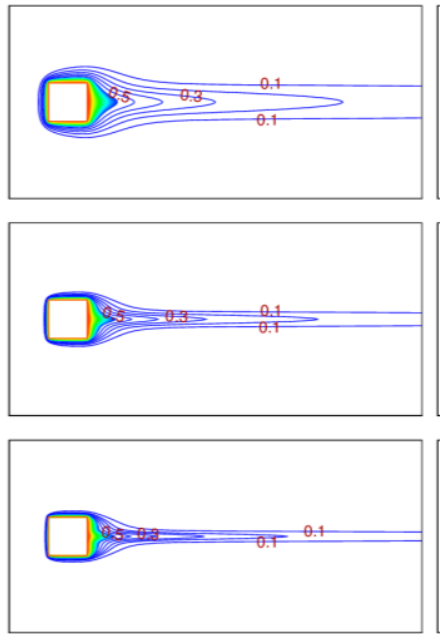

(c) $R i=1$

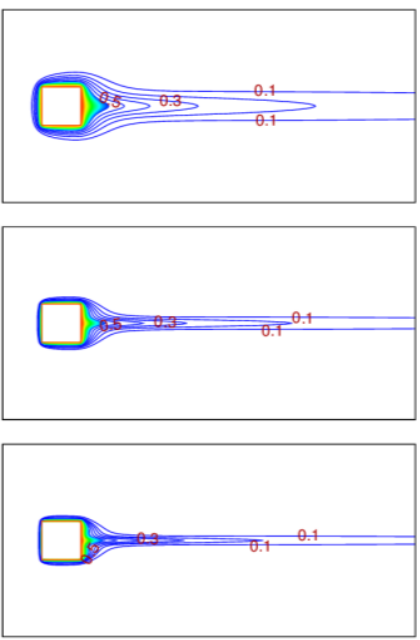

Figure 10. Time-averaged isotherms for different values of $\operatorname{Re}$ and $R i$ at $\varphi=5 \%$ : (a) $R i=0,(b) R i=0.5$, (c) $\mathrm{Ri}=1$.

(a) $R i=0$

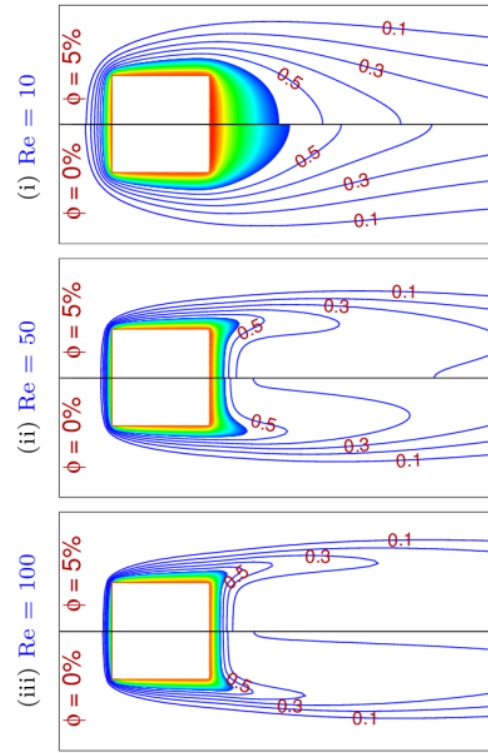

(b) $R i=1$

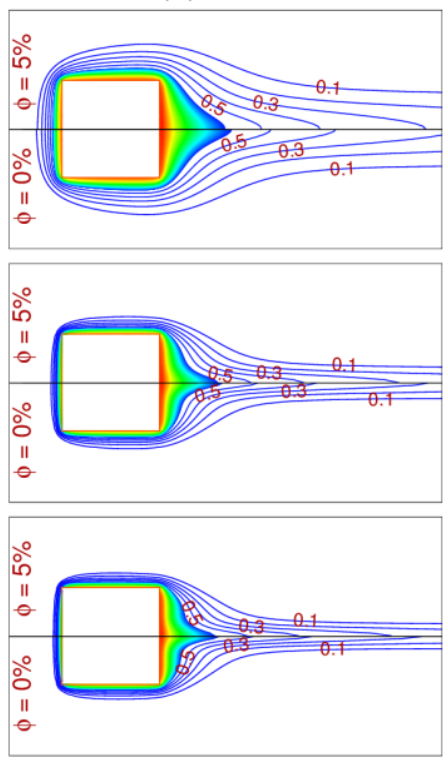

Figure 11. Comparison of isotherms at $\varphi=0 \%$ and $5 \%$ for different values of $\operatorname{Re}$ for $(\mathbf{a}) \operatorname{Ri}=0$ and (b) $\mathrm{Ri}=1$. 
(a) $R i=0$

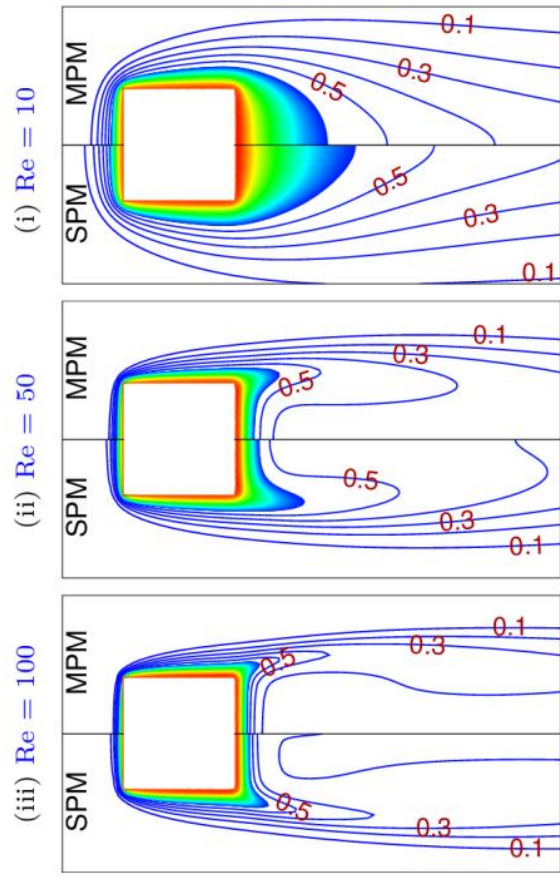

(b) $R i=1$
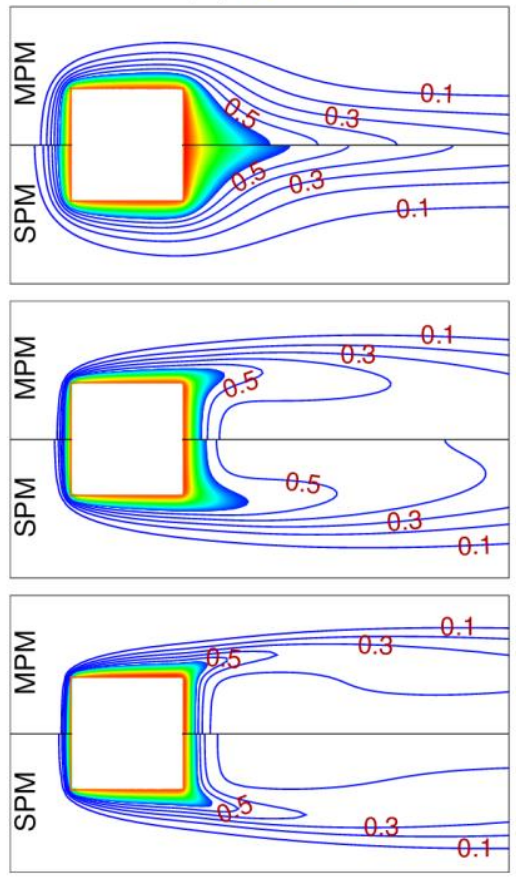

Figure 12. Comparison of isotherms on the basis of single-phase and multi-phase modelling approach at different values of $\operatorname{Re}$ and $R i$ at $\varphi=5 \%$ : (a) $\mathrm{Ri}=0$, and (b) $\mathrm{Ri}=1$.

\subsubsection{Local and Mean Nusselt Number of the Cylinder}

The local Nusselt number $\left(N u_{l}\right)$ variation over the square cylinder is presented in Figure 13a-i. The effects of $R e, R i$, and $\varphi$ values on $N u_{l}$ for the considered parameters are shown. Peak values of $N u_{l}$ occur at the corners of the square cylinder due to large temperature gradients. The maximum value of $N u_{l}$ is noticed at the windward side (i.e., $\mathrm{CD}$ ) of the cylinder, which increases with $R e$, for given values of $R i$ and $\varphi$ (see, subplot $(\mathrm{a}-\mathrm{c})$ of Figure 13). A significant enhancement is noticed for $N u_{l}$ magnitude when $R i$ is increased for a given $\operatorname{Re}$ and $\varphi$ (see, subplot (d-f) of Figure 13). Similarly, effects of the addition of nanoparticles are measurable at the windward surface (CD) of the cylinder at the given value of $R i$ and $R e$.

The mean Nusselt number $\left(N u_{M}\right)$ variation is shown in Figure 14a-c. Since $\varphi$ changes the thermophysical properties of the nanofluids, accordingly the mean Nusselt number increases with an increase in $\varphi$. A significant increment in $N u_{M}$ is observed at higher values of $\varphi$ and $R e$, which justifies the use of nanofluids. An increment of $R e$ and $R i$ rises the convective heat transfer rate and fluid momentum that creates a temperature gradient in the vicinity of the cylinder resulting in enhanced $N u_{M}$. The quantitative comparison of $N u_{M}$ value obtained from the single-phase and multi-phase models is presented in Table 3. It is found that the use of the MPM approach indicates a higher value of $N u_{M}$ than the SPM approach for the same operating parameters. A similar finding is reported in the literature for Reynolds number in the range of $10 \leq R e \leq 40$ [24]. 
(a) $\phi=0 \%$

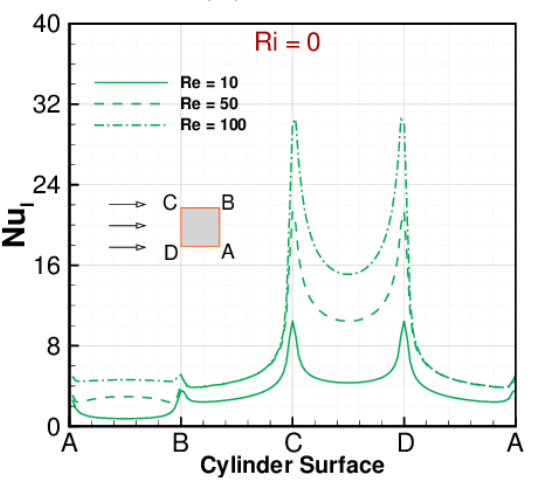

(d) $R e=10$

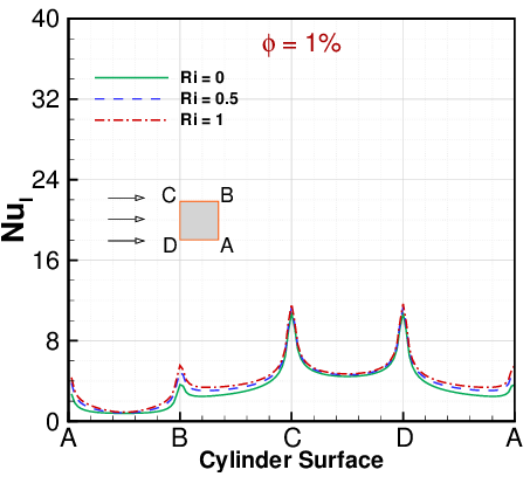

(g) $R i=0$

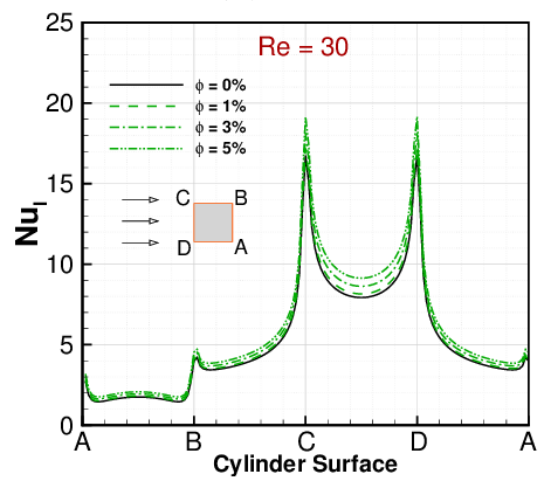

(b) $\phi=3 \%$

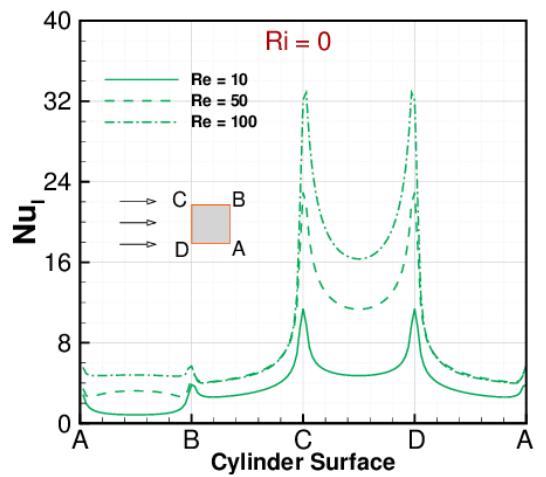

(e) $R e=50$

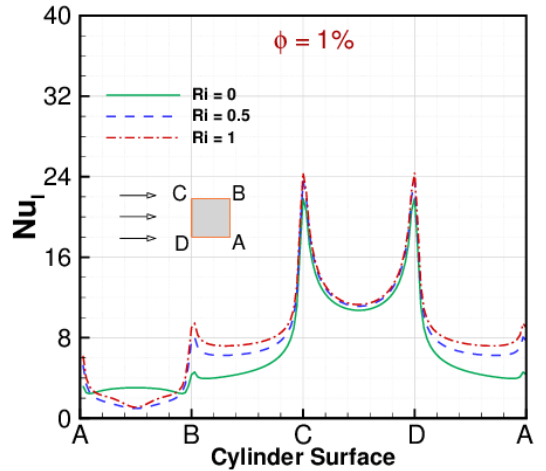

(h) $R i=0.5$

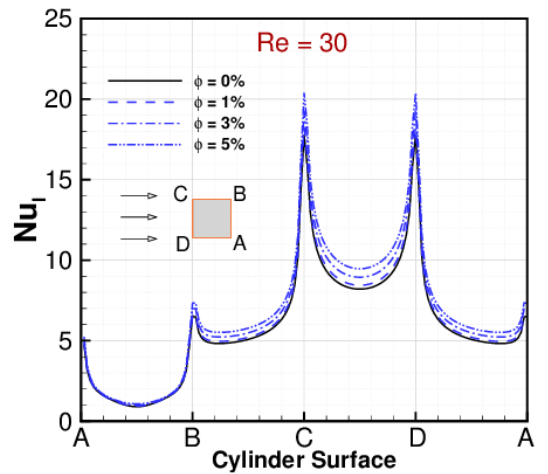

(c) $\phi=5 \%$

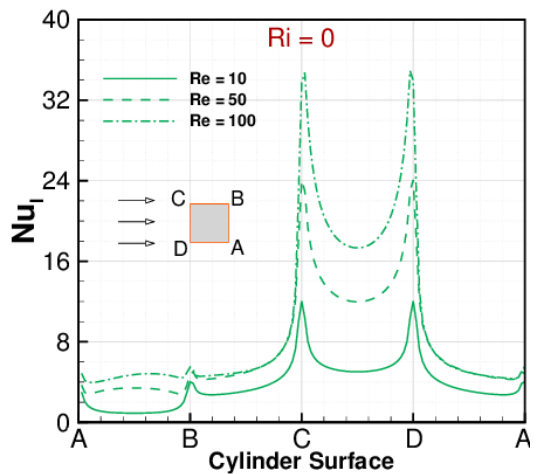

(f) $R e=100$

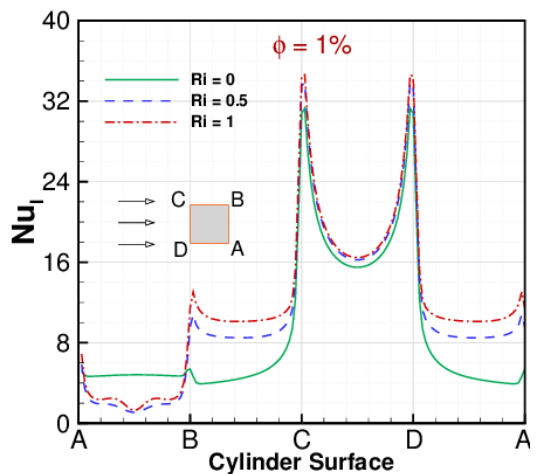

(i) $R i=1.0$

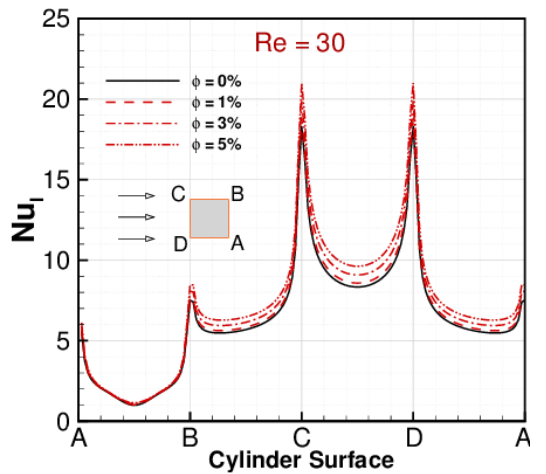

Figure 13. Local Nusselt number $\left(N u_{l}\right)$ distributions on the surface of a heated square cylinder at the considered parameters: (a) $\varphi=0 \%$, (b) $\varphi=3 \%$, (c) $\varphi=5 \%$, (d) $\operatorname{Re}=10,(\mathbf{e}) \operatorname{Re}=50$, (f) $\operatorname{Re}=100,(\mathrm{~g}) \operatorname{Ri}=0$, (h) $\operatorname{Ri}=0.5$ and (i) $\operatorname{Ri}=1$. 

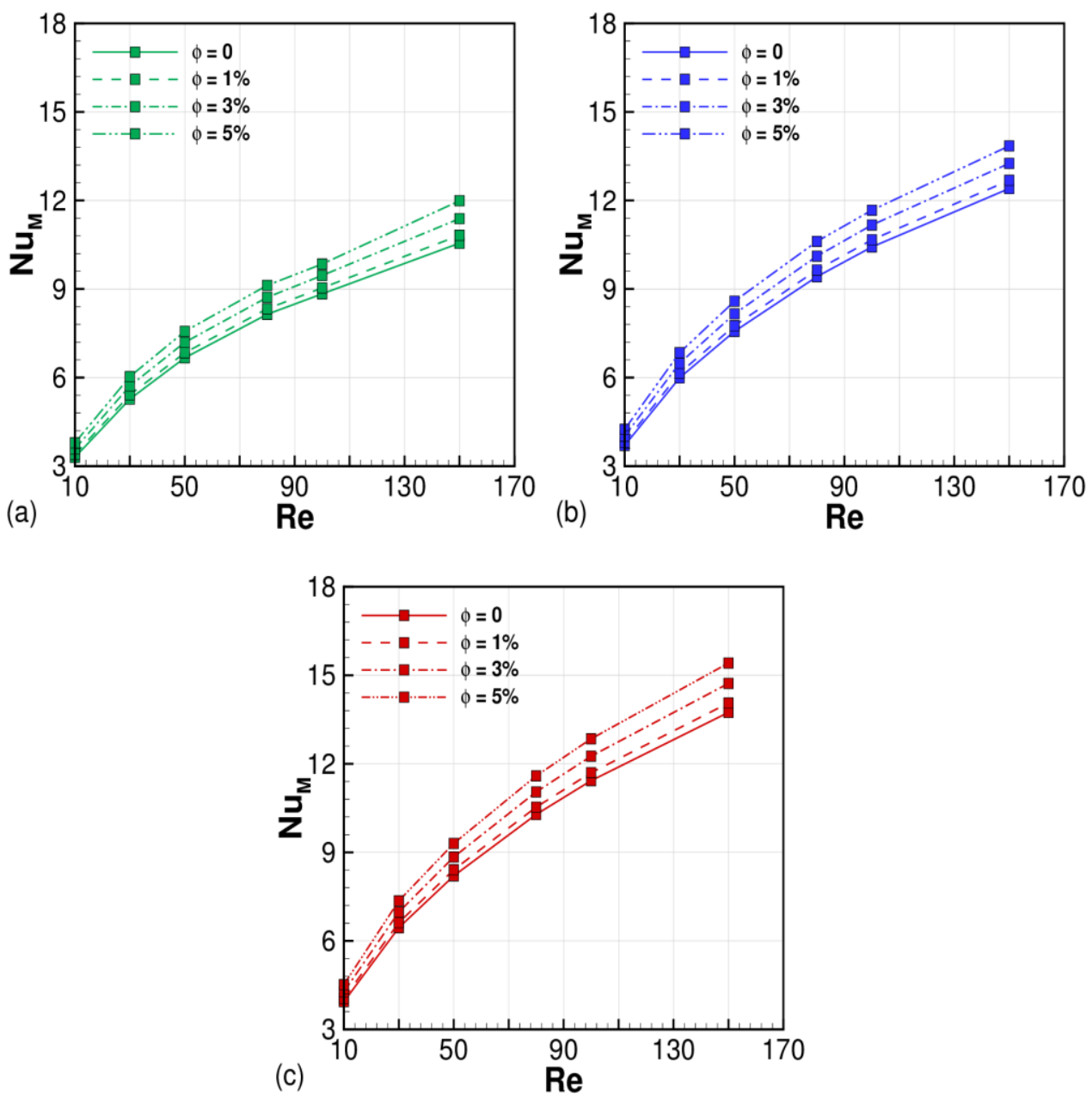

Figure 14. Mean Nusselt number $\left(N u_{M}\right)$ as a function of $\operatorname{Re}$ for different values of $\varphi$ at $R i$; (a) 0 , (b) 0.5 , and (c) 1 .

Table 3. Comparison of drag coefficient $\left(C_{D}\right.$ and Nusselt number $\left(N u_{\mathrm{M}}\right)$ of the cylinder with the literature.

\begin{tabular}{|c|c|c|c|c|c|c|c|c|c|}
\hline \multirow{3}{*}{$R e$} & \multicolumn{9}{|c|}{$C_{D}$} \\
\hline & \multicolumn{3}{|c|}{$R i=0$} & \multicolumn{3}{|c|}{$R i=0.5$} & \multicolumn{3}{|c|}{$R i=1.0$} \\
\hline & $a^{a}$ & $\mathbf{b}^{\mathbf{b}}$ & Error (\%) & $a^{a}$ & $\mathbf{b}^{\mathbf{b}}$ & Error (\%) & $a^{a}$ & $\mathbf{b}^{\mathbf{b}}$ & Error (\%) \\
\hline 1 & 13.995 & 13.836 & 1.137 & 22.125 & 21.883 & 1.094 & 29.32 & 28.965 & 1.211 \\
\hline 5 & 4.878 & 4.8 & 1.6 & 8.012 & 7.977 & 0.437 & 10.325 & 10.424 & 0.959 \\
\hline 10 & 3.322 & 3.318 & 0.121 & 5.443 & 5.436 & 0.129 & 7.029 & 7.012 & 0.242 \\
\hline 20 & 2.351 & 2.353 & 0.086 & 3.861 & 3.859 & 0.052 & 4.981 & 4.989 & 0.161 \\
\hline 30 & 1.978 & 1.977 & 0.051 & 3.247 & 3.248 & 0.031 & 4.181 & 4.189 & 0.192 \\
\hline \multirow[t]{2}{*}{40} & 1.764 & 1.765 & 0.057 & 2.896 & 2.895 & 0.035 & 3.733 & 3.742 & 0.242 \\
\hline & \multicolumn{9}{|c|}{$N u_{M}$} \\
\hline \multirow[t]{2}{*}{$\operatorname{Re}$} & \multicolumn{3}{|c|}{$R i=0$} & \multicolumn{3}{|c|}{$R i=0.5$} & \multicolumn{3}{|c|}{$R i=1.0$} \\
\hline & $a^{a}$ & $\mathbf{b}^{\mathbf{b}}$ & Error (\%) & $a^{a}$ & $\mathbf{b}^{\mathbf{b}}$ & Error (\%) & $\mathbf{a}^{\mathrm{a}}$ & $\mathbf{b}^{\mathbf{b}}$ & Error (\%) \\
\hline 1 & 0.681 & 0.696 & 2.203 & 0.771 & 0.758 & 1.687 & 0.781 & 0.793 & 1.537 \\
\hline 5 & 1.212 & 1.191 & 1.733 & 1.322 & 1.329 & 0.53 & 1.422 & 1.405 & 1.196 \\
\hline 10 & 1.544 & 1.551 & 0.454 & 1.733 & 1.744 & 0.635 & 1.833 & 1.852 & 1.037 \\
\hline 20 & 2.051 & 2.035 & 0.781 & 2.322 & 2.312 & 0.431 & 2.433 & 2.457 & 0.987 \\
\hline 30 & 2.367 & 2.388 & 0.888 & 2.722 & 2.727 & 0.184 & 2.922 & 2.911 & 0.377 \\
\hline 40 & 2.612 & 2.596 & 0.613 & 3.05 & 3.08 & 0.984 & 3.254 & 3.288 & 1.054 \\
\hline
\end{tabular}


Table 3. Cont.

\begin{tabular}{ccccccc}
\hline & \multicolumn{7}{c}{$\boldsymbol{N} \boldsymbol{u}_{\boldsymbol{M}}$} \\
\cline { 2 - 7 } $\boldsymbol{N}$ & \multicolumn{5}{c}{$\boldsymbol{R}=\mathbf{1 0}$} & $\boldsymbol{R} \boldsymbol{e}=\mathbf{4 0}$ \\
\cline { 2 - 7 } & $\mathbf{a}^{\mathbf{a}}$ & $\mathbf{c}^{\mathbf{c}}$ & Error (\%) & $\mathbf{a}^{\mathbf{a}}$ & $\mathbf{c}^{\mathbf{c}}$ & Error (\%) \\
\hline 0 & 3.811 & 3.81 & 0.027 & 7.101 & 7.1 & 0.015 \\
\hline 1 & 3.829 & 3.824 & 0.131 & 7.11 & 7.104 & 0.085 \\
\hline 3 & 3.944 & 3.937 & 0.178 & 7.33 & 7.343 & 0.178 \\
\hline 5 & 4.158 & 4.166 & 0.193 & 7.822 & 7.812 & 0.128 \\
\hline
\end{tabular}

$\mathrm{a}^{\mathrm{a}}$ Present study, $\mathrm{b}^{\mathrm{b}}$ Sharma et al. [52], $\mathrm{c}^{\mathrm{c}}$ Selvakumar and Dhinakaran [24].

\subsubsection{Thermal Performance}

Figure $15 \mathrm{a}-\mathrm{c}$ displays the heat transfer enhancement ratio $\left(\mathrm{E}=N u_{M} / N u_{M 0}\right)$ as a function of $R e$ for different values of $\varphi$. Here, $N u_{M 0}$ represents the Nusselt number value of the base fluid (at $\varphi=0$ ). The enhancement ratio increases with $\varphi$ and decreases with $R e$. It almost remains constant at a low value of $\varphi(\sim 1)$ regardless of the $R i$ variation. Further, there are no significant effects on $\mathrm{E}$ under thermal buoyancy conditions. Moreover, higher heat transfer enhancement occurs at low Reynolds number and at high volume fraction. At the same time, the drag coefficient of the cylinder and viscosity of fluid is also greater in magnitude. Table 4 presents the Nusselt number $\left(N u_{M}\right)$ deviation between the single-phase modelling and multi-phase modelling approaches at $R i=1.0$. A percentage difference less than $1 \%$ in $N u_{M}$ is observed between the two models.
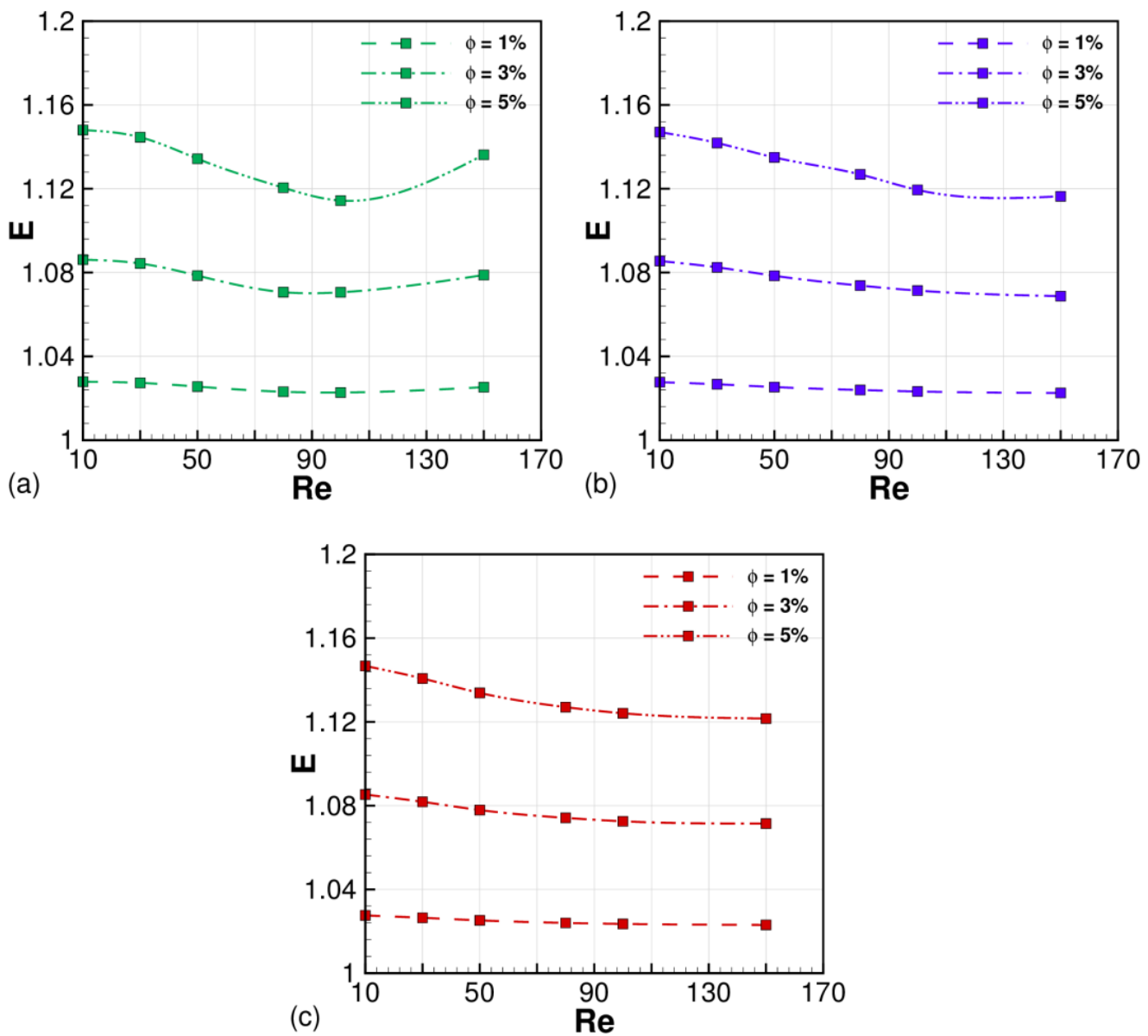

Figure 15. Heat transfer enhancement ratio (E) as function of $\boldsymbol{R} \boldsymbol{e}$ for different values of $\varphi$ at $R i$; (a) 0 , (b) 0.5 , and (c) 1 . 
Table 4. Nusselt number $\left(N u_{M}\right.$ deviation between single-phase modelling and multi-phase modelling approaches at $R i=1.0$.

\begin{tabular}{ccccccccccc}
\hline \multirow{2}{*}{$\boldsymbol{R} \boldsymbol{e}$} & \multicolumn{3}{c}{$\boldsymbol{\varphi} \mathbf{\mathbf { 1 } \%}$} & \multicolumn{3}{c}{$\boldsymbol{\varphi = 3 \%}$} & \multicolumn{3}{c}{$\boldsymbol{\varphi}=\mathbf{5 \%}$} \\
\cline { 2 - 11 } & $\mathbf{M P M}$ & SPM & Deviation (\%) & MPM & SPM & Deviation (\%) & MPM & SPM & Deviation (\%) \\
\hline 10 & 3.392 & 3.381 & 0.326 & 3.585 & 3.55 & 0.986 & 3.789 & 3.768 & 0.558 \\
\hline 30 & 5.415 & 5.393 & 0.408 & 5.716 & 5.687 & 0.51 & 6.033 & 5.986 & 0.786 \\
\hline 50 & 6.84 & 6.818 & 0.323 & 7.193 & 7.127 & 0.927 & 7.565 & 7.496 & 0.921 \\
\hline 80 & 8.331 & 8.325 & 0.073 & 8.718 & 8.702 & 0.184 & 9.124 & 9.1 & 0.264 \\
\hline 100 & 9.037 & 9.021 & 0.178 & 9.46 & 9.453 & 0.075 & 9.847 & 9.883 & 0.365 \\
\hline 150 & 10.821 & 10.773 & 0.446 & 11.386 & 11.277 & 0.967 & 11.991 & 11.877 & 0.96 \\
\hline
\end{tabular}

\section{Conclusions}

Mixed convective heat transfer from a heated square cylinder placed in a uniform flow is studied numerically with $\mathrm{Al}_{2} \mathrm{O}_{3}$-water nanofluids as the working fluid using the two-phase mixture model. This model gives better consistency due to the inclusion of the multi-phase approach while considering slip velocity between nanoparticles and base fluid. The fluid flow and heat transfer behaviour are presented through vorticity, streamlines, and thermal contours. By increasing the solid volume fraction, minor variations in the flow and thermal patterns are observed for the base fluid under thermal buoyancy condition. For a fixed $R i$, the recirculation bubble increases with $R e$. Magnitude of vorticity increases with an increase in $R e$ and $R i$. Streamlines and vorticity contours qualitatively show similar trends for both the single-phase and multi-phase approaches. The magnitude of the pressure coefficient decreases with an increase in $R e$ from 10 to 100 . Minor variation in $C_{p}$ is observed with variation in nanoparticle volume fraction from 0 to $5 \%$. A slight rise in $C_{D}$ is observed for nanofluids when $R e$ varies from 10 to 50 . Beyond this value, no significant change in $C_{D}$ is observed for any value of $\varphi$. A remarkable change in isotherm patterns can be observed at a lower value of Re only with the change in $R i$. A significant enhancement in heat transfer is noticed for $N u_{l}$ magnitude when $R i$ is increased for a given $\operatorname{Re}$ and $\varphi$. The local and mean Nusselt numbers increase with Reynolds number, Richardson number, and nanoparticle volume fraction. For instance, the mean Nusselt number of nanofluids at $\operatorname{Re}=100, \varphi=5 \%$, and $R i=1$ is approximately $12.4 \%$ higher than that of the base fluid. A comparison of the calculated value of $N u_{M}$ is made between the single-phase and multi-phase models. In the mixture model, effective conductivity and viscosity of nanofluids are found to be sensitive parameters for heat transfer calculation. The overall thermal enhancement ratio increases with $\varphi$ and decreases with $R e$, and almost remains constant at a lower value of $\varphi$ regardless of the variation in $R i$.

To expand this study as future work, the effect of nanolayer thickness and nanoparticles diameter on the overall heat transfer rate can be studied for different shapes of bluff bodies at higher thermal buoyancy.

Author Contributions: Conceptualization, R.S.R.; methodology, R.S.R.; software, R.S.R.; validation, R.S.R..; formal analysis, R.S.R.; investigation, R.S.R., S.D. and M.M.A.; resources, R.S.R.; data curation, R.S.R.; writing—original draft preparation, R.S.R.; writing-review and editing, R.S.R., S.D. and M.M.A.; visualization, R.S.R.; supervision, S.D.; project administration, S.D.; funding acquisition, S.D. All authors have read and agreed to the published version of the manuscript.

Funding: This research was funded by given by the Khalifa University of Science and Technology through Grants CIRA-2020-057.

Institutional Review Board Statement: Not applicable.

Informed Consent Statement: Not applicable. 
Data Availability Statement: The data that support the findings of this study are available within the article.

Conflicts of Interest: The authors declare no conflict of interest.

\section{Nomenclature}

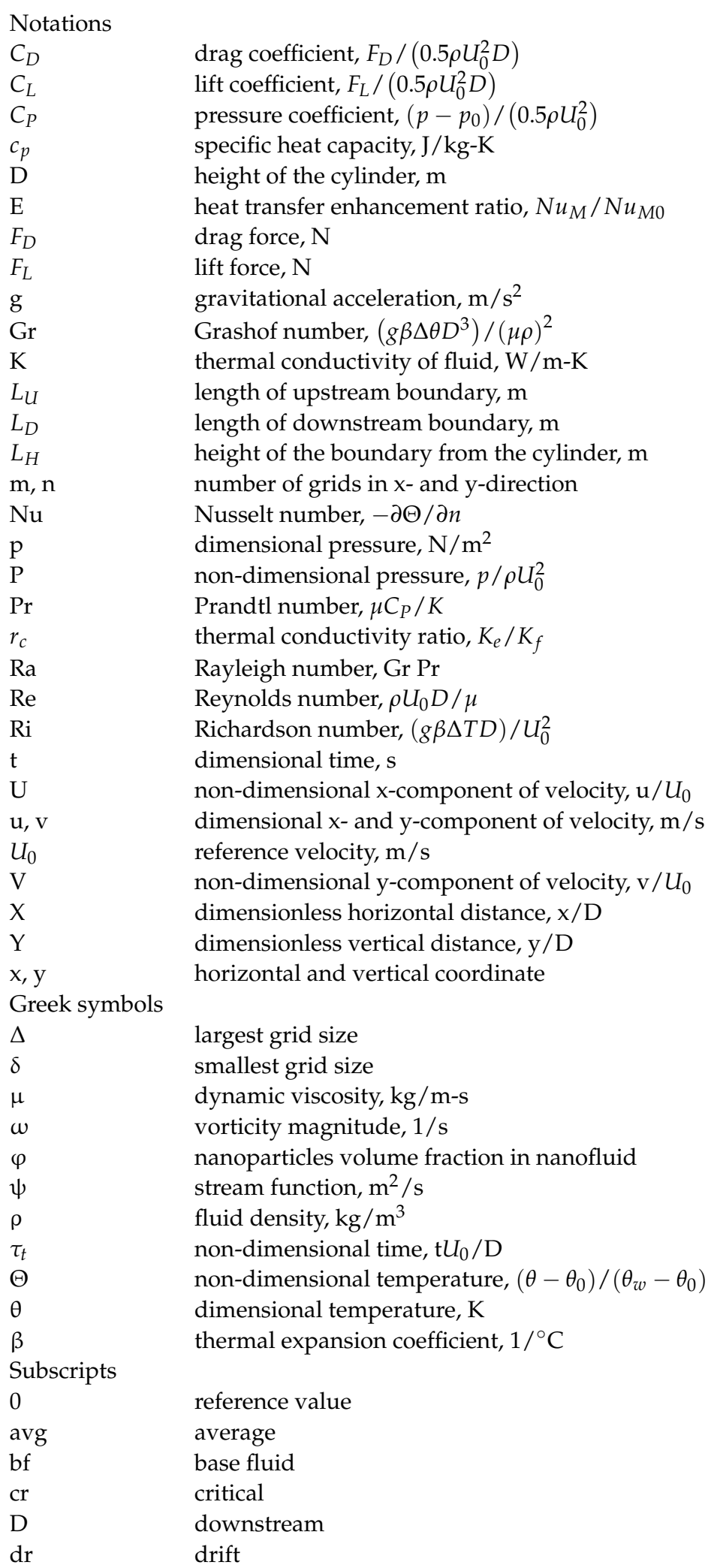




$\begin{array}{ll}\text { e } & \text { effective } \\ \text { f } & \text { fluid } \\ \text { l } & \text { local value of variable } \\ \mathrm{M} & \text { mean value } \\ \mathrm{m} & \text { mixture } \\ \mathrm{nf} & \text { nanofluid } \\ \mathrm{np} & \text { nanoparticles } \\ \mathrm{nl} & \text { nano layer } \\ \mathrm{p} & \text { particle } \\ \mathrm{s} & \text { solid } \\ \mathrm{U} & \text { upstream } \\ \mathrm{w} & \text { wall }\end{array}$

\section{References}

1. Sivashanmugam, P. Application of nanofluids in heat transfer. Overv. Heat Transf. Phenom. 2012, 16. [CrossRef]

2. Wong, K.V.; De Leon, O. Applications of nanofluids: Current and future. Nanotechnol. Energy 2017, 105-132. [CrossRef]

3. Sajid, M.U.; Ali, H.M. Recent advances in application of nanofluids in heat transfer devices: A critical review. Renew. Sustain. Energy Rev. 2019, 103, 556-592. [CrossRef]

4. Rafati, M.; Hamidi, A.; Niaser, M.S. Application of nanofluids in computer cooling systems (heat transfer performance of nanofluids). Appl. Therm. Eng. 2012, 45, 9-14. [CrossRef]

5. Huminic, G.; Huminic, A. Application of nanofluids in heat exchangers: A review. Renew. Sustain. Energy Rev. 2012, 16, 5625-5638. [CrossRef]

6. Kulkarni, D.P.; Das, D.K.; Vajjha, R.S. Application of nanofluids in heating buildings and reducing pollution. Appl. Energy 2009, 86, 2566-2573. [CrossRef]

7. Okonkwo, E.C.; Wole-Osho, I.; Almanassra, I.W.; Abdullatif, Y.M.; Al-Ansari, T. An updated review of nanofluids in various heat transfer devices. J. Therm. Anal. Calorim. 2021, 145, 2817-2872. [CrossRef]

8. Senthilraja, S.; Karthikeyan, M.; Gangadevi, R. Nanofluid applications in future automobiles: Comprehensive review of existing data. Nano-Micro Lett. 2010, 2, 306-310.

9. Bhogare, R.A.; Kothawale, B. A review on applications and challenges of nanofluids as coolant in automobile radiator. Int. J. Sci. Res. Publ. 2013, 3, 1-11.

10. Arani, A.A.; Amani, J. Experimental study on the effect of $\mathrm{TiO}_{2}$-water nanofluid on heat transfer and pressure drop. Exp. Therm. Fluid Sci. 2012, 42, 107-115.

11. Kayhani, M.; Soltanzadeh, H.; Heyhat, M.; Nazari, M.; Kowsary, F. Experimental study of convective heat transfer and pressure drop of $\mathrm{TiO}_{2}$ /water nanofluid. Int. Commun. Heat Mass Transf. 2012, 39, 456-462. [CrossRef]

12. Esfe, M.H.; Saedodin, S.; Wongwises, S.; Toghraie, D. An experimental study on the effect of diameter on thermal conductivity and dynamic viscosity of Fe/water nanofluids. J. Therm. Anal. Calorim. 2015, 119, 1817-1824.

13. Vanaki, S.M.; Ganesan, P.; Mohammed, H.A. Numerical study of convective heat transfer of nanofluids: A review. Renew. Sustain. Energy Rev. 2016, 54, 1212-1239. [CrossRef]

14. Choi, H.; Jeon, W.P.; Kim, J. Control of flow over a bluff body. Annu. Rev. Fluid Mech. 2008, 40, 113-139.

15. Derakhshandeh, J.; Alam, M.M. A review of bluff body wakes. Ocean Eng. 2019, 182, 475-488.

16. Kakaç, S.; Pramuanjaroenkij, A. Review of convective heat transfer enhancement with nanofluids. Int. J. Heat Mass Transf. 2009, 52, 3187-3196.

17. Etminan-Farooji, V.; Ebrahimnia-Bajestan, E.; Niazmand, H.; Wongwises, S. Unconfined laminar nanofluid flow and heat transfer around a square cylinder. Int. J. Heat Mass Transf. 2012, 55, 1475-1485.

18. Valipour, M.S.; Masoodi, R.; Rashidi, S.; Bovand, M.; Mirhosseini, M. A numerical study on convection around a square cylinder using $\mathrm{Al}_{2} \mathrm{O}_{3}-\mathrm{H}_{2} \mathrm{O}$ nanofluid. Therm. Sci. 2014, 18, 1305-1314.

19. Bahiraei, M. A comprehensive review on different numerical approaches for simulation in nanofluids: Traditional and novel techniques. J. Dispers. Sci. Technol. 2014, 35, 984-996.

20. Moraveji, M.K.; Ardehali, R.M. CFD modeling (comparing single and two-phase approaches) on thermal performance of $\mathrm{Al}_{2} \mathrm{O}_{3} /$ water nanofluid in mini-channel heat sink. Int. Commun. Heat Mass Transf. 2013, 44, 157-164. [CrossRef]

21. Ansys Fluent Users Guide. Release 15.0, November 2013 and ANSYS Fluent 12.0. Theory Guide; SAS IP Inc.: Canonsburg, Pennsylvania, 2009.

22. Bizhaem, H.K.; Abbassi, A. Numerical study on heat transfer and entropy generation of developing laminar nanofluid flow in helical tube using two-phase mixture model. Adv. Powder Technol. 2017, 28, 2110-2125. [CrossRef]

23. Karimi, A.; Al-Rashed, A.A.; Afrand, M.; Mahian, O.; Wongwises, S.; Shahsavar, A. The effects of tape insert material on the flow and heat transfer in a nanofluid-based double tube heat exchanger: Two-phase mixture model. Int. J. Mech. Sci. 2019, 156, 397-409.

24. Selvakumar, R.D.; Dhinakaran, S. Forced convective heat transfer of nanofluids around a circular bluff body with the effects of slip velocity using a multi-phase mixture model. Int. J. Heat Mass Transf. 2017, 106, 816-828. 
25. Pakravan, H.A.; Yaghoubi, M. Analysis of nanoparticles migration on natural convective heat transfer of nanofluids. Int. J. Therm. Sci. 2013, 68, 79-93.

26. Alinia, M.; Ganji, D.; Gorji-Bandpy, M. Numerical study of mixed convection in an inclined two sided lid driven cavity filled with nanofluid using two-phase mixture model. Int. Commun. Heat Mass Transf. 2011, 38, 1428-1435.

27. Esfe, M.H.; Barzegarian, R.; Bahiraei, M. A 3D numerical study on natural convection flow of nanofluid inside a cubical cavity equipped with porous fins using two-phase mixture model. Adv. Powder Technol. 2020, 31, 2480-2492.

28. Garoosi, F.; Rohani, B.; Rashidi, M.M. Two-phase mixture modeling of mixed convection of nanofluids in a square cavity with internal and external heating. Powder Technol. 2015, 275, 304-321.

29. Darzi, A.A.R.; Farhadi, M.; Lavasani, A.M. Two phase mixture model of nano-enhanced mixed convection heat transfer in finned enclosure. Chem. Eng. Res. Des. 2016, 111, 294-304. [CrossRef]

30. Ebrahimi, A.; Rikhtegar, F.; Sabaghan, A.; Roohi, E. Heat transfer and entropy generation in a microchannel with longitudinal vortex generators using nanofluids. Energy 2016, 101, 190-201.

31. Naranjani, B.; Roohi, E.; Ebrahimi, A. Thermal and hydraulic performance analysis of a heat sink with corrugated channels and nanofluids. J. Therm. Anal. Calorim. 2020, 1-12. [CrossRef]

32. Saieesh, A.T.S.V.; Prasad, M. Analysis of forced convective heat transfer through nanofluids around a square cylinder using Eulerian-Eulerian mixture modelling. Int. J. Nanotechnol. 2021, 18, 719-739. [CrossRef]

33. Arjun, K.S.; Rakesh, K. Heat transfer in magnetohydrodynamic nanofluid flow past a circular cylinder. Phys. Fluids 2020, $32,045112$.

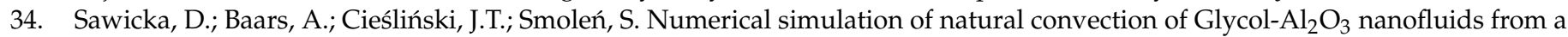
horizontal cylinder. Heat Transf. Eng. 2020, 42, 328-336. [CrossRef]

35. Godson, L.; Raja, B.; Lal, D.M.; Wongwises, S.E.A. Enhancement of heat transfer using nanofluids-An overview. Renew. Sustain. Energy Rev. 2010, 14, 629-641. [CrossRef]

36. Moraveji, M.K.; Darabi, M.; Haddad, S.M.H.; Davarnejad, R. Modeling of convective heat transfer of a nanofluid in the developing region of tube flow with computational fluid dynamics. Int. Commun. Heat Mass Transf. 2011, 38, 1291-1295.

37. Brinkman, H. The viscosity of concentrated suspensions and solutions. J. Chem. Phys. 1952, 20, 571.

38. Xuan, Y.; Roetzel, W. Conceptions for heat transfer correlation of nanofluids. Int. J. Heat Mass Transf. 2000, 43, $3701-3707$.

39. Xie, H.; Fujii, M.; Zhang, X. Effect of interfacial nanolayer on the effective thermal conductivity of nanoparticle-fluid mixture. Int. J. Heat Mass Transf. 2005, 48, 2926-2932.

40. Khanafer, K.; Vafai, K. A critical synthesis of thermophysical characteristics of nanofluids. Int. J. Heat Mass Transf. 2011, 54, $4410-4428$.

41. El-Batsh, H.; Doheim, M.; Hassan, A. On the application of mixture model for two-phase flow induced corrosion in a complex pipeline configuration. Appl. Math. Model. 2012, 36, 5686-5699.

42. Manninen, M.; Taivassalo, V.; Kallio, S. On the Mixture Model for Multi-Phase Flow; Valtion Teknillinen Tutkimuskeskus: Espoo, Finland, 1996.

43. Schiller, L. A drag coefficient correlation. Zeit. Ver. Deutsch. Ing. 1933, 77, 318-320.

44. Abu-Nada, E. Effects of variable viscosity and thermal conductivity of $\mathrm{Al}_{2} \mathrm{O}_{3}$-water nanofluid on heat transfer enhancement in natural convection. Int. J. Heat Fluid Flow 2009, 30, 679-690. [CrossRef]

45. Hamzah, N.S.A.; Kandasamy, R.; Muhammad, R. Thermal radiation energy on squeezed $\mathrm{MHD}$ flow of $\mathrm{Cu}_{1} \mathrm{Al}_{2} \mathrm{O}_{3}$ and $\mathrm{CNTs}-$ nanofluid over a sensor surface. Alex. Eng. J. 2016, 55, 2405-2421. [CrossRef]

46. Sasmal, C.; Chhabra, R. Laminar natural convection from a heated square cylinder immersed in power-law liquids. J. Non-Newton. Fluid Mech. 2011, 166, 811-830.

47. Ansys, A.F. 14.0 Theory Guide; ANSYS Inc.: Canonsburg, PA, USA, 2011; pp. 218-221.

48. Park, D.; Yang, K.S. Flow instabilities in the wake of a rounded square cylinder. J. Fluid Mech. 2016, $793,915$.

49. Saha, A.K.; Muralidhar, K.; Biswas, G. Transition and chaos in two-dimensional flow past a square cylinder. J. Eng. Mech. 2000, $126,523-532$.

50. Jiang, H.; Cheng, L.; An, H. Three-dimensional wake transition of a square cylinder. J. Fluid Mech 2018, 842, $102-127$.

51. Sohankar, A.; Norbergb, C.; Davidson, L. Numerical simulation of unsteady low-Reynolds number flow around rectangular cylinders at incidence. J. Wind Eng. Ind. Aerodyn. 1997, 69, 189-201.

52. Abdelhamid, T.; Alam, M.M.; Islam, M. Heat transfer and flow around cylinder: Effect of corner radius and Reynolds number. Int. J. Heat Mass Transf. 2021, 171, 121105.

53. Bai, H.; Alam, M.M. Dependence of square cylinder wake on Reynolds number. Phys. Fluids 2018, 30, 015102.

54. Sharma, N.; Dhiman, A.K.; Kumar, S. Mixed convection flow and heat transfer across a square cylinder under the influence of aiding buoyancy at low Reynolds numbers. Int. J. Heat Mass Transf. 2012, 55, 2601-2614. [CrossRef]

55. Gupta, R.K.; Chandra, A.; Gupta, R.K. Buoyancy-driven convective heat transfer from a semi-circular cylinder for various confinements. Sadhana 2018, 43, 1-18. [CrossRef]

56. Srinivas, A.T.; Bharti, R.P.; Chhabra, R.P. Mixed convection heat transfer from a cylinder in power-law fluids: Effect of aiding buoyancy. Ind. Eng. Chem. Res. 2009, 48, 9735-9754. [CrossRef] 